\title{
Desigualdades Intraestaduais no Espírito Santo: uma abordagem espacial exploratória ${ }^{\S}$
}

Leonardo de Magalhães Leite ${ }^{1}$

Matheus Albergaria de Magalhães²

Resumo: O presente trabalho tem como objetivo identificar padrões espaciais de crescimento econômico dos municípios do estado do Espírito Santo. Para tanto, utiliza-se uma base de dados referentes ao PIB per capita desses municípios, englobando o período 1999-2007. Do mesmo modo, são empregados métodos de Análise Estatística Descritiva Espacial (AEDE), procurando-se verificar a formação de clusters de municípios com características econômicas semelhantes. Os resultados obtidos demonstram que: (i) há evidências de ocorrência de transbordamentos espaciais entre os municípios analisados; (ii) ocorrem nítidas diferenças entre municípios localizados no norte ou sul do estado; (iii) ao longo do período 1999-2007, vem ocorrendo um padrão de crescimento onde municípios na porção noroeste do estado tendem, em média, a crescer mais do que municípios localizados na porção sudoeste. Esses resultados são importantes no sentido de fornecerem primeiras evidências relacionadas à importância de fatores geográficos no processo de crescimento dos municípios do Espírito Santo, podendo ser úteis para a formulação e implementação de políticas regionais que visem a promover o desenvolvimento dessas localidades.

Palavras-chave: economia regional; transbordamentos espaciais, Espírito Santo. JEL: O18, R12, R58.

\footnotetext{
§ Os autores agradecem os comentários e sugestões de Alexandre Ottoni, Ana Paula Vescovi, Mirta Sataka e aos participantes do I Encontro de Economia do Espírito Santo. Um agradecimento especial a dois pareceristas anônimos deste periódico, por fornecerem valiosas sugestões à versão anterior do trabalho. Pela editoração das figuras contidas no trabalho, fica registrado um agradecimento a João Vitor André. Vale a ressalva usual de que os erros e idiossincrasias remanescentes devem-se única e exclusivamente aos autores.

1 Coordenador de Estudos Setoriais, Rede de Estudos Macroeconômicos (MACRO) do Instituto Jones dos Santos Neves (IJSN). E-mail: leonardo.leite@ijsn.es.gov.br

2 Especialista em Pesquisas Governamentais do Instituto Jones dos Santos Neves (IJSN). Pesquisador da Rede de Estudos Macroeconômicos (MACRO) do IJSN. E-mail: matheus@ijsn.es.gov.br
} 


\title{
Intrastate inequalities in the Espirito Santo: an exploratory spatial approach
}

\begin{abstract}
This paper aims to identify spatial growth patterns in the state of Espírito Santo's municipalities. In doing so, it is used a database containing per capita GDP measures of these municipalities. We also employ methods related to Descriptive Spatial Statistical Analysis, trying to check for the formation of clusters of similar municipalities. Results obtained show that: (i) there are evidences of spatial spillovers among the state's municipalities; (ii) there are remarkable differences between municipalities located in the northern and southern parts of the state; (iii) during the 1999-2007 period, there has been an empirical pattern where northwest area's municipalities tend to grow faster than southwest area's. These results are important in the sense of providing first empirical evidences related to the importance of geographical factors for the growth process of Espírito Santo's municipalities, being useful for the formulation and implementation of regional policies aimed to promote these localities' development.
\end{abstract}

Key-words: regional economics, spatial spillovers, State of Espírito Santo.

JEL: O18, R12, R58.

\section{Introdução}

A compreensão das desigualdades entre os municípios de um mesmo estado equivale a um dos maiores desafios da atualidade em termos de políticas públicas. Em particular, entender as razões pelas quais distintas localidades situadas em áreas relativamente próximas apresentam marcantes diferenças em relação a seu grau de desenvolvimento econômico pode constituir a fundamentação de políticas voltadas para a redução dessas desigualdades, bem como evitar armadilhas de pobreza, por exemplo.

Nas últimas décadas, o estado do Espírito Santo vem registrando bons resultados em relação a seus indicadores socioeconômicos. Em termos de crescimento, o estado vem apresentando, desde o ano de 1985, uma taxa próxima a 5\%, superior à média nacional (4\%). Em relação ao longo prazo, o Espírito Santo, mesmo partindo de um baixo nível inicial de crescimento, convergiu à média do país nas últimas décadas, o que colocou o estado dentre os primeiros colocados no ranking de PIB per capita do Brasil (Bonelli e Levy, 2010).

Por outro lado, vale à pena ressaltar que o progresso ocorrido no estado não se restringiu apenas ao campo econômico. Entre os anos de 2001 e 2008, o estado do Espírito Santo registrou consideráveis avanços em alguns de seus 
principais indicadores sociais. Assim, ao longo desse período, a proporção de pobres declinou de $32,8 \%$ para $15,2 \%$, ao mesmo tempo em que cerca de 500 mil indivíduos saíram da pobreza e 250 mil deixaram a condição de indigência (Vescovi e Castro, 2008). De fato, o Espírito Santo foi o único estado brasileiro onde a redução da pobreza foi acompanhada por uma concomitante redução da desigualdade (Barros et al., 2010).

Apesar do considerável progresso alcançado pelo estado como um todo, ainda persistem diferenças entre os municípios do Espírito Santo. Por exemplo, em termos de investimentos previstos para o período 2008 a 2013, há resultados demonstrando a ocorrência de padrões de concentração espacial e especialização setorial na maioria dos projetos de investimento analisados (Magalhães e Toscano, 2011) ${ }^{1}$. Do mesmo modo, nota-se a ocorrência de significativa concentração da população do estado em um número relativamente reduzido de cidades, um padrão empírico nos moldes de distribuições de cauda longa (Magalhães e Toscano, 2010b). Adicionalmente, em termos de redução das desigualdades de renda per capita entre os municípios e regiões do estado, evidências recentes apontam para um quadro de divergência; isto é, ao longo dos últimos anos, vem aumentando as disparidades em termos de evolução da renda per capita entre localidades do Espírito Santo (Magalhães e Toscano, 2010a).

Embora os esforços de pesquisa supracitados sejam úteis no sentido de identificar distintos padrões de desenvolvimento entre localidades do estado, os resultados reportados negligenciam o papel desempenho pela dimensão espacial. Por exemplo, estimativas que não levem em conta a importância de complementariedades espaciais entre as unidades de análise podem vir a ser afetadas por conta disso. De fato, a importância da dimensão espacial tende a ser tanto maior quanto mais desagregada for a unidade de análise (e.g., municípios ou regiões de um mesmo estado).

Por conta disso, o objetivo do presente trabalho equivale a identificar padrões de crescimento entre os municípios do estado, agrupando-os em clusters baseados em características semelhantes. Em última instância, o intuito básico do trabalho equivale à identificação de áreas de crescimento comum interiores território estadual ${ }^{2}$. Para tanto, será realizada uma análise exploratória de padrões de crescimento dos municípios do estado do Espírito Santo, com base em técnicas de Análise Estatística Descritiva Espacial (AEDE).

\footnotetext{
1 Atualmente, existem evidências apontando para o início de um processo de desconcentração dos projetos de investimento previstos para o Espírito Santo (Taveira et al.; 2010). Vale a ressalva de que, apesar da ocorrência de um processo nesses moldes, ainda persiste um alto grau de concentração espacial desses projetos no estado (Magalhães e Toscano, 2011).

2 Vale ressaltar a possibilidade de que o padrão de crescimento dos municípios do Espírito Santo pode vir a ser influenciado pela atividade econômica de estados vizinhos, como Bahia, Minas Gerais e Rio de Janeiro, por exemplo. Para maiores detalhes a esse respeito, ver a seção de testes de robustez do presente trabalho.
} 
O trabalho está dividido da seguinte maneira: a segunda seção contém uma breve resenha parcial da literatura relacionada ao tema, enquanto a terceira seção apresenta a base de dados e a metodologia utilizadas no trabalho. Por sua vez, a quarta seção apresenta os principais resultados obtidos, com a quinta seção apresentando resultados de testes de robustez. Finalmente, a sexta seção contém as principais conclusões do trabalho, ao mesmo tempo em que fornece sugestões de pesquisa futura.

\section{Literatura relacionada}

A presente seção apresenta uma revisão parcial da literatura relacionada ao tema. Basicamente, são apresentadas e descritas referências equivalentes a aplicações da AEDE em distintos contextos como forma de situar o trabalho dentro dessa área de estudo.

Maranduba e Almeida (2009) procuram analisar a distribuição espacial dos repasses da lei estadual n. ${ }^{0}$ 12.040/95 em Minas Gerais, conhecida como lei Robin Hood. Basicamente, os autores pretendem investigar se, entre os anos de 2001 e 2005, ocorre um processo de convergência nos repasses financeiros dessa lei. Através da estatística $I$ de $\mathrm{Moran}^{3}$, os autores concluem que tanto no ano de 2001 quanto no ano de 2005, ocorre um padrão de autocorrelação espacial positiva nos repasses da lei Robin Hood: municípios que recebem altas (baixas) parcelas dos recursos repassados tendem a possuir vizinhos que também recebem altas (baixas) parcelas das mesmas. Adicionalmente, investigam a ocorrência de autocorrelação espacial local através de uma análise do tipo Local Indicators of Spatial Association (LISA). Neste caso, tanto em 2001 quanto em 2005, verificam que os padrões espaciais encontrados nos repasses da lei estão em sintonia com as características socioeconômicas do estado. Entretanto, dado o caráter estático dessa primeira investigação, os autores procedem com uma análise de convergência espacial para verificar se municípios mais pobres passaram a receber mais recursos ao longo do tempo. Após a estimação de um modelo com componentes espaciais, a conclusão dos autores é que os repasses da lei Robin Hood “(...) não estão contribuindo para que municípios mais pobres do estado recebam mais recursos provenientes de municípios mais ricos (...)" (Maranduba e Almeida 2009; p. 597); isto é, não está ocorrendo um padrão de convergência espacial dos repasses em análise.

Outro campo de aplicação de análises espaciais equivale à agricultura. Em Perobelli et al. (2007), os autores realizam uma análise da estrutura espacial da produtividade agrícola no Brasil ao longo do período compreendido entre os anos de 1991 e 2003. Utilizando como recorte

3 Em Maranduba e Almeida (2009) foi utilizada uma matriz W de $k$ vizinhos mais próximos, com $k=5$, normalizada na linha. Este procedimento torna a soma dos pesos espaciais iguais a 1 em cada linha de W, procedimento que, segundo Tyszler (2006, p. 48): “(...) permite uma comparabilidade direta entre diferentes pesos da mesma matriz (...)”; isto é, torna mais fácil sua interpretação. Maiores detalhes adiante. 
espacial as 558 microrregiões brasileiras, os autores demonstram que, em geral, a produtividade agrícola vem aumentando desde o começo da década de 90. Além disso, reportam a ocorrência de forte padrão de autocorrelação espacial, que também vem aumentando ao longo do tempo. Baseados nos resultados, os autores conseguem inferir que a intensidade desse padrão de autocorrelação espacial pode ser explicada pelo aumento do número de pontos de alavancagem, ou seja, regiões com grande influência sobre a magnitude do coeficiente I de Moran. Os autores concluem que clusters de alta produtividade agrícola no Brasil se fortalecem na região sudeste, principalmente no interior de São Paulo e litoral do Nordeste. Ao longo do tempo, na região Centro-Oeste, especialmente em Mato Grosso, também ocorre o surgimento de clusters. Em síntese, os autores conseguem confirmar a hipótese de que existe dependência espacial da produtividade agrícola no território brasileiro (Perobelli et al., 2007).

Almeida, Perobelli e Ferreira (2008) complementam o estudo anterior. O objetivo dos autores equivale a testar a ocorrência de convergência espacial da produtividade agrícola no Brasil entre os anos de 1991 e 2003, dividindo o período em quatro subamostras, definidas de acordo com distintos ambientes macroeconômicos vigentes no país: 1991 a 1994; 1995 a 1999; 2000 a 2003; e o período completo, de 1991 a 2003. Após corroborarem empiricamente a hipótese de autocorrelação espacial global da produtividade agrícola média, Almeida, Perobelli e Ferreira (2008) utilizam vários modelos econométricos espaciais para verificar a ocorrência de padrões de convergência. Os autores concluem que, no período como um todo (1991-2003), ocorre convergência da produtividade, mas a uma velocidade relativamente pequena. Segundo eles, o subperíodo que mais contribuiu para um padrão de convergência foi o período posterior ao processo de abertura econômica no país, compreendido entre os anos de 1991 e 1994. Portanto, os autores conseguem detectar a ocorrência de convergência absoluta, mas não os canais pelos quais esse fenômeno ocorre. Os autores finalizam seu trabalho sugerindo como tema de pesquisa futura a incorporação de variáveis explicativas para a realização de uma análise de convergência condicional.

Outro trabalho que utiliza procedimentos da AEDE equivale a Pimentel e Haddad (2004). Um dos objetivos dos autores é verificar a existência de regimes espaciais para a renda per capita em Minas Gerais utilizando as microrregiões como unidade de análise e três grandes setores: agricultura, indústria e serviços. Através de dados dos Censos de 1991 e 2000, os autores calculam o I de Moran para cada setor ao longo dos anos selecionados. Os resultados obtidos demonstram que, em todos os setores, ao longo dos períodos analisados, existe um padrão de autocorrelação espacial positiva, sendo que na agropecuária esse padrão tende a ser mais forte. Para localizar a ocorrência de regimes espaciais, os autores utilizam a estatística LISA, atentando para a constituição de dois regimes distintos: um cluster de alta 
renda na região leste do estado, principalmente no Triângulo Mineiro, e outro cluster de baixa renda nas regiões norte e nordeste de Minas Gerais, com resultados mais significativos para o setor agropecuário.

Na literatura internacional, pode-se citar, a título de exemplo, alguns trabalhos que analisam a dependência espacial da renda ou do produto regional. Em López (2007), a questão central a ser respondida é a seguinte: o processo de abertura comercial no México aumentou ou reduziu as disparidades regionais em termos de crescimento econômico? Após apresentar estimativas obtidas via Mínimos Quadrados Ordinários (MQO) para testar a hipótese de convergência de renda per capita, o autor verifica que o índice de Moran aponta para a presença de autocorrelação espacial nos resíduos da regressão. Segundo ele, a heterogeneidade espacial em modelos de crescimento pode ser resultado de efeitos de fronteira (transbordamentos), ocorridos durante processos de crescimento econômico regional.

Para atender à questão de heterogeneidade espacial, López (2007) propõe uma regionalização baseada em autocorrelações locais da produtividade do trabalho em 2003 por meio da estatística LISA. No caso, a intenção básica do autor, a partir desse procedimento, equivale à criação de uma variável binária a ser incluída em um modelo econométrico, de modo a checar a ocorrência de diferenças em processos de convergência no centro ou periferia. Por conta disso, o autor considera como municípios do centro $(C)$ aqueles que possuem $I$ de Moran local para produtividade do trabalho positiva, e como periferia $(P)$ aqueles municípios que possuem $I$ de Moran local negativo para a mesma variável. Ao incluir essas características em um modelo de regressão com defasagem espacial no termo de erro, o autor conclui que a periferia (região mais pobre do país, localizada ao sul) tende a ser mais homogênea, possuindo maior velocidade de convergência. Por outro lado, o centro (região mais rica e mais ao norte) possui heterogeneidade espacial, com a formação de clubes de convergência.

O estudo da heterogeneidade espacial também pode ser encontrado em Le Gallo e Ertur (2003). Neste trabalho, os autores se propõem a analisar a dinâmica do produto per capita regional na Europa ao longo do tempo e espaço. Para isso, utilizam métodos da AEDE em uma amostra de regiões européias para o período compreendido entre os anos de 1980 e 1995. Os autores partem do pressuposto de que existem vários fatores que conduzem à dependência geográfica - ou interações espaciais - entre regiões, como comércio, difusão de tecnologia, conhecimento e outras externalidades ou spillovers mais genéricos. Sendo assim, pretendem identificar onde ocorrem as interações entre os PIB per capita de 138 regiões de 11 países europeus ao longo do período analisado.

Os autores encontram fortes evidências de presença de autocorrelação espacial positiva em sua amostra. Além disso, como atesta o valor da estatística $I$ de 
Moran, esse padrão de dependência espacial vai crescendo ao longo do tempo, o que implica que as regiões tornam-se gradativamente mais interrelacionadas umas com as outras. Para detectar regimes espaciais, os autores utilizam a estatística LISA e percebem a formação de três clusters de baixo PIB per capita (Portugal e grande parte da Espanha; sul da Itália; Grécia) e um cluster de alto PIB per capita (Alemanha; partes da França; Bélgica; Holanda; norte da Itália) que persistem ao longo do tempo.

Através das pesquisas citadas nesta seção, pode-se perceber que a análise exploratória de dados espaciais (AEDE) equivale a um conjunto de ferramentas voltadas para a detecção de padrões espaciais. Além disso, as análises podem ser efetuadas de forma estática - considerando apenas um instante de tempo - ou de forma dinâmica - levando em consideração vários períodos ou trabalhando com variáveis em taxas. Por conta disso, a análise subsequente empregará técnicas nesses moldes na tentativa de registrar a ocorrência de padrões de dependência espacial entre medidas de PIB per capita dos municípios do Espírito Santo.

\section{Base de dados e Metodologia}

\subsection{Base de dados}

As variáveis utilizadas neste trabalho equivalem a dados de Produto Interno Bruto (PIB) e população referentes aos municípios do estado do Espírito Santo. A fonte primária desses dados é o Instituto Brasileiro de Geografia e Estatística (IBGE). No caso do estado do Espírito Santo, existe atualmente uma parceria entre o IBGE e o Instituto Jones dos Santos Neves (IJSN), onde essas instituições realizam uma divulgação conjunta dos dados ${ }^{4}$.

O período amostral analisado equivale ao intervalo compreendido entre os anos de 1999 e 2007. Esse período foi escolhido com base na disponibilidade de dados, já que ocorreram mudanças na metodologia de cálculo do PIB que impossibilitam uma comparação direta com dados anteriores ao ano de 1999 (Magalhães e Toscano, 2010a; Moulin, 2010).

Ao longo da análise subsequente, serão utilizados indicadores de PIB referentes a distintos setores da economia estadual, assim como indicadores derivados a partir dessa variável ${ }^{5}$.

\footnotetext{
4 Para mais informações sobre o assunto, consultar o website do IJSN: <http://www.ijsn.es.gov.br>.

5 O Apêndice A do trabalho apresenta informações socioeconômicas sobre o estado do Espírito Santo, com ênfase em seus municípios e divisões administrativas.
} 
Ao longo do presente trabalho, a hipótese básica a ser testada é de que a variável de interesse - o Produto Interno Bruto (PIB) per capita - seja em termos de níveis ou taxas, em termos agregados ou setoriais, possui um comportamento aleatório no espaço ${ }^{6}$. Basicamente, essa hipótese equivale ao fato de que o PIB de um dado município não deveria, a princípio, ser afetado pela localização desse município; isto é, o PIB de uma localidade não deve ser correlacionado com o PIB de localidades vizinhas. Caso essa hipótese seja corroborada, não deveriam existir, a princípio, regiões que exibam padrões espaciais distintos das demais, ou seja, não existiriam aglomerações (clusters) municipais.

Em meio a esse contexto, há a possibilidade de ocorrência de "efeitostransbordamento" (spillovers) entre municípios localizados em uma mesma região geográfica. Ou seja, pode ocorrer um processo de difusão espacial do PIB dos municípios. Um processo clássico de difusão pode ser descrito a partir de uma situação onde há, por exemplo, um grande investimento em alguma localidade - choque inicial - que aumenta a demanda por bens e serviços dentro do próprio município e nos vizinhos, gerando um ciclo virtuoso que contamina toda a região: aumenta a demanda, que gera aumentos de produção, que aumenta a renda do município, e assim por diante. No caso do presente contexto, passa a ser importante a identificação do choque inicial, assim como das regiões beneficiadas por um processo nos moldes descritos acima.

Conforme citado acima, a análise desenvolvida no presente contexto equivale à Análise Exploratória de Dados Espaciais (AEDE), correspondente a uma primeira aproximação no tocante a trabalhos que buscam captar interações espaciais entre distintas unidades de interesse. Enquanto técnica exploratória, a AEDE busca identificar se os dados sob análise estão ou não distribuídos aleatoriamente no espaço; isto é, identificar ao longo da região em estudo, qual o comportamento assumido pelas variáveis em termos de padrões ou regimes espaciais7.

Em alguns trabalhos empíricos aplicados, o processo de determinação da não-aleatoriedade espacial fica restrito à inspeção visual de mapas - de fato, o benefício deste procedimento equivale a sua simplicidade analítica. Entretanto, como esse tipo de análise pode estar condicionado a critérios subjetivos, também faz-se necessária uma análise mais rigorosa do tema.

6 A escolha da variável PIB per capita para a análise desenvolvida neste trabalho foi feita em consonância com a literatura especializada sobre o tema. Ver, a título de exemplo, Barro e Sala-i-Martin (1995).

7 Por exemplo, buscando identificar se a violência possui um processo de difusão espacial, Messner et al. (1999, p.425) caracterizam a AEDE como “(...) a collection of techniques to describe and visualize spatial distributions, identify atypical locations or spatial outliers, discover patterns of spatial association, clusters or hot spots, and suggest spatial regimes or other forms of spatial heterogeneity (...)”. Assim, a princípio, a AEDE equivale a uma modalidade de análise restrita ao campo exploratório, fornecendo insights para posteriores processos de inferência estatística de maior grau de sofisticação. Para uma exposição didática dessa técnica, ver: Almeida (2009). 
Assim, para identificar a presença de autocorrelação espacial, ou seja, para testar a hipótese de aleatoriedade espacial nos dados, a técnica tradicionalmente utilizada para essa finalidade equivale ao índice de Moran (Moran, 1948). Especificamente, o índice de Moran equivale ao primeiro coeficiente de autocorrelação espacial, denominado $I$ de Moran, que pode variar entre -1 e +1 e possui valor esperado igual a $-1 /(n-1)$. No caso desse indicador, valores positivos e significativos indicam autocorrelação espacial positiva, ao passo que valores negativos e significativos indicam autocorrelação espacial negativa.

Para construir formalmente uma medida de vizinhança entre municípios, deve-se formar uma matriz de ponderação espacial. Trata-se de uma matriz, comumente chamada de $W$, de dimensão $n$ por $n$ ( $\operatorname{com} n$ indicando o número de unidades espaciais em análise), onde cada célula $w_{i j}$ representa o grau de interação, definido por algum critério específico, entre duas regiões quaisquer, $i$ e $j$. No caso dos municípios espírito santenses, essa matriz teria a seguinte forma genérica:

$W_{78 \times 78}=\left[\begin{array}{ccc}w_{1 ; 1} & \cdots & w_{1 ; 78} \\ \vdots & \ddots & \vdots \\ w_{78 ; 1} & \cdots & w_{78 ; 78}\end{array}\right] \quad W_{78 \times 78}=\left[\begin{array}{ccc}w_{1 ; 1} & \cdots & w_{1 ; 78} \\ \vdots & \ddots & \vdots \\ w_{78 ; 1} & \cdots & w_{78 ; 78}\end{array}\right]$

Trata-se de uma matriz de dimensão $78 \times 78$, que equivale à quantidade total de municípios do estado do Espírito Santo. Neste trabalho, a matriz $W$ escolhida será uma matriz de contiguidade, uma vez que esta representação parece ser aquela que melhor se adequa às características territoriais do estado, já que os municípios se distribuem de maneira aproximadamente uniforme sobre a área do estado e não existem municípios ilhados. Uma vez que não existem fronteiras comuns situadas em pontos ou vértices, utilizou-se uma matriz de contiguidade do tipo rainha - embora, no caso deste trabalho, não haja diferença quanto à escolha de matrizes do tipo rainha ou torre ${ }^{8}$. Portanto, o valor de cada célula será estabelecido da seguinte maneira:

$$
w_{i j}=\left\{\begin{array}{l}
1 \quad \text { se há fronteira entre } i \text { e } j \\
0 \quad \text { se não há fronteira entre } i \text { e } j
\end{array}\right.
$$

8 A diferença entre esses dois tipos de matriz é que, caso dois municípios possuam apenas um ponto como fronteira comum, as matrizes rainha os consideram como vizinhos, enquanto as matrizes torre não os consideram (Le Sage, 1999, pp. 9-10). 


$$
w_{i j}=\left\{\begin{array}{l}
1 \quad \text { se há fronteira entre } i \text { e } j \\
0 \quad \text { se não há fronteira entre } i \text { e } j
\end{array}\right.
$$

onde $i$ e $j$ referem-se a dois municípios quaisquer.

A partir da definição formal do critério de vizinhança, a estatística $I$ de Moran pode ser representada em notação matricial e com pesos de $W$ normalizados da seguinte forma ${ }^{9}$ :

$$
I=\frac{z^{\prime} W z}{z^{\prime} z} I=\frac{z^{\prime} W z}{z^{\prime} z}
$$

onde $I$ equivale ao coeficiente da estatística $I$ de Moran, $z$ representa os valores da variável de interesse padronizada e $W z$ representa os valores médios da variável de interesse padronizada de municípios vizinhos. De fato, como afirmam Anselin, Sridharan e Gholston (2007), esta estatística equivale essencialmente a uma medida de correlação cruzada de produto que incorpora o espaço por meio da matriz $W$.

Além do próprio valor de $I$ e de sua significância estatística, outra possibilidade, derivada da primeira, para averiguar padrões de autocorrelação espacial equivale ao diagrama de dispersão de Moran. Trata-se de um diagrama de dispersão envolvendo a variável padronizada em estudo $(z)$ contra a média dos vizinhos, isto é, seu valor defasado espacialmente $(\mathrm{Wz})$. De acordo com o padrão apresentado pela nuvem de pontos de um diagrama de dispersão nesses moldes, passa a ser possível inferir a respeito de possíveis padrões de autocorrelação espacial. Na realidade, $I$ equivale formalmente ao coeficiente de uma regressão de $W z$ em função de $z$ : quanto maior a autocorrelação espacial (valor de $I$ ), maior a inclinação dessa reta de regressão (Anselin, 1993) ${ }^{10}$.

Além das informações acerca do padrão global de associação linear espacial, também se faz importante a identificação de aglomerações espaciais em nível local. Ou seja, uma vez que se verifique a existência de padrões de autocorrelação espacial, passa a ser importante a localização de regimes espaciais específicos.

9 A normalização da matriz $W$ torna mais fácil a interpretação dos pesos espaciais $w_{i j}$. Para maiores detalhes e uma descrição formal desse procedimento de normalização, ver: Tyszler (2006).

10 De acordo com Anselin (1993, p.8): “(...) the interpretation of Moran's I as a bivariate regression coefficient is perfectly general, and in fact applies to any statistic that can be expressed as a ratio of a quadratic form and its sum of squares (...)". Um exemplo de estatística que também pode ser interpretada nesses moldes equivale ao coeficiente Durbin-Watson, utilizado para testar a ocorrência de autocorrelação em séries temporais. 
Anselin (1995) sugeriu um indicador que busca capturar padrões locais de autocorrelação espacial que sejam estatisticamente significativos. Trata-se dos indicadores do tipo LISA, conforme citado acima e que permitem avaliar agrupamentos espaciais locais ao redor de uma localização individual; isto é, a indicação de clusters espaciais estatisticamente significativos (Anselin, 1995, p. 94). Dentre este grupo de indicadores está o coeficiente $I$ de Moran local, caracterizado como $I_{i}$ e expresso formalmente como:

$$
I_{i}=z_{i} \sum_{j=1}^{J} w_{i j} z_{j} I_{i}=z_{i} \sum_{j=1}^{J} w_{i j} z_{j}
$$

onde $I_{i}$ equivale ao valor do coeficiente $I$ de Moran local, isto é, de um município específico $i ; z_{i}$ refere-se ao valor padronizado da variável de interesse no município $i$ e $z_{j}$ o valor padronizado da variável em um município $j$ pertencente ao conjunto vizinhança $J_{i}$ de $i$. Como neste trabalho utiliza-se uma matriz de vizinhança de contiguidade binária, $w_{i j}$ assume valor unitário caso o município $j$ pertença ao conjunto vizinhança de $i$; isto é, caso faça fronteira com ele. Caso contrário, $w_{i j}=0$.

Assim, ao considerar apenas os vizinhos de cada observação, de acordo com uma matriz $W$ previamente escolhida, esta estatística apresenta-se como eficaz na detecção de padrões locais de associação espacial, como clusters, por exemplo.

Por fim, cabe ressaltar que tanto a estatística global $(I)$ quanto a local $\left(I_{i}\right)$ de autocorrelação espacial podem ser empregadas de forma bivariada. Assim, por exemplo, pode-se observar qual padrão espacial predomina entre determinada variável de um município qualquer e outra variável de municípios vizinhos.

Em relação à inferência, as estatísticas de associação espacial calculadas podem ser significativas ou não. O procedimento utilizado geralmente equivale à permutação condicional, a partir do qual se constrói uma função de distribuição empírica para avaliar a significância da estatística observada (Anselin, 1995) ${ }^{11}$. Com base nesta operação, encontra-se a probabilidade segundo a qual a estatística em questão é significativa, ou, dito de outra maneira, encontra-se o seu p-valor.

11 Anselin (1995) demonstra que a utilização de permutação condicional equivale a um procedimento necessário, dadas as dificuldades de se obter a função de distribuição das estatísticas de associação espacial. Este procedimento possui caráter condicional, uma vez que o valor $y_{i}$ em uma localização $i$ qualquer é mantido fixo, enquanto os valores restantes $y_{j}$ são aleatoriamente permutados $n$ vezes. A cada permutação, o valor da estatística espacial pode ser calculado, resultando em uma função de distribuição empírica que constitui base para avaliação da significância da estatística observada. 


\section{Resultados}

Nesta seção são apresentados os resultados do trabalho, divididos em três etapas. Na primeira, será realizada uma breve caracterização das variáveis utilizadas, com base em algumas estatísticas descritivas desconsiderando-se os efeitos espaciais. Em um segundo momento, será discutida a presença da autocorrelação espacial global nos dados. Caso seja confirmada a hipótese de que o comportamento do PIB per capita dos municípios em análise tende a transbordar para municípios vizinhos, serão investigados, na terceira etapa, os locais onde esses transbordamentos ocorrem.

\subsection{Estatísticas descritivas}

Analisando a tabela 1, pode-se perceber que o PIB per capita médio dos municípios espírito santenses evoluiu de uma média de 4,4 mil reais em 1999 para 12,3 mil reais em 2007 (aumento de 179,5\%). Ao mesmo tempo, a heterogeneidade (medida via desvio-padrão) entre os municípios, de acordo com o PIB per capita, também aumenta: de 3,15 para 10,88 mil reais (aumento de 245,4\%) entre os anos de 1999 e 2007.

TABELA 1. ESTATÍSTICAS DAS VARIÁVEIS (EM MIL, R\$) - 1999/2007

\begin{tabular}{c|c|c|c|c|c|c|c|c}
\hline \multirow{2}{*}{ Ano } & \multicolumn{2}{|c|}{ PIB per capita } & \multicolumn{2}{c|}{$\begin{array}{c}\text { PIB per capita } \\
\text { Agropecuária }\end{array}$} & $\begin{array}{c}\text { PIB per capita } \\
\text { Indústria }\end{array}$ & \multicolumn{2}{|c}{$\begin{array}{c}\text { PIB per capita } \\
\text { Serviços }\end{array}$} \\
\cline { 2 - 9 } & Média & DP* & Média & DP* & Média & DP* & Média & DP* $^{*}$ \\
\hline 1999 & 4,40 & 3,15 & 1,31 & 0,88 & 0,79 & 1,52 & 1,95 & 1,28 \\
\hline 2000 & 5,21 & 3,59 & 1,70 & 1,10 & 0,94 & 1,86 & 2,18 & 1,44 \\
\hline 2001 & 4,99 & 3,35 & 1,12 & 0,79 & 0,96 & 1,59 & 2,40 & 1,40 \\
\hline 2002 & 5,45 & 4,03 & 1,10 & 0,87 & 1,22 & 2,20 & 2,57 & 1,59 \\
\hline 2003 & 6,52 & 5,41 & 1,38 & 0,92 & 1,60 & 3,94 & 2,95 & 1,75 \\
\hline 2004 & 7,85 & 6,44 & 1,83 & 1,66 & 1,89 & 3,80 & 3,43 & 2,32 \\
\hline 2005 & 9,14 & 9,06 & 1,96 & 1,66 & 2,53 & 5,90 & 3,83 & 2,91 \\
\hline 2006 & 9,95 & 8,55 & 2,23 & 1,78 & 2,61 & 5,29 & 4,22 & 2,82 \\
\hline $\begin{array}{c}\text { Taxa Média } \\
\text { Crescimento }\end{array}$ & 94,22 & 34,90 & 65,97 & 49,81 & 119,12 & 62,91 & 93,04 & 17,47 \\
\hline
\end{tabular}

Fonte: cálculos dos autores. *(Desvio Padrão)

A decomposição do PIB per capita agregado nos três grandes setores de atividade (agropecuária, indústria e serviços) indica que a maior taxa média de crescimento entre 1999 e 2007 ocorreu na indústria (119,1\%), enquanto a agropecuária foi o setor cuja taxa de crescimento médio registrou o menor 
valor (66\%, aproximadamente). O crescimento industrial esteve acompanhado por uma maior heterogeneidade intermunicipal, dado que o desvio padrão desse setor salta de aproximadamente $\mathrm{R} \$ 1,5$ mil em 1999 para quase $\mathrm{R} \$$ 7,9 mil, em 2007.

\subsection{Testes de Autocorrelação Espacial Global}

A tabela 2 contém resultados relacionados ao indicador $I$ de Moran para o PIB per capita dos municípios do estado ${ }^{12}$.

TABELA 2. I DE MORAN PARA PIB PER CAPITA DOS MUNICÍPIOS DO ESPÍRITO SANTO, ANOS SELECIONADOS, 1999/2007

\begin{tabular}{c|c|c|c|c}
\hline PIB per capita & $I$ de Moran & Média & Desvio-padrão & Probabilidade \\
\hline 1999 & $0,0805^{*}$ & $-0,013$ & 0,0616 & 0,095 \\
2000 & 0,0523 & $-0,013$ & 0,0615 & 0,139 \\
2001 & $0,1382^{* *}$ & $-0,012$ & 0,0612 & 0,029 \\
2002 & $0,0999^{*}$ & $-0,015$ & 0,0613 & 0,062 \\
2003 & 0,0410 & $-0,014$ & 0,0648 & 0,192 \\
2004 & $0,0886^{*}$ & $-0,014$ & 0,0612 & 0,070 \\
2005 & 0,0557 & $-0,015$ & 0,0588 & 0,136 \\
2006 & $0,1085^{* *}$ & $-0,014$ & 0,0612 & 0,044 \\
2007 & 0,0677 & $-0,016$ & 0,0626 & 0,110 \\
\hline
\end{tabular}

Fonte: cálculos dos autores.

Nota: Os termos $(*),\left({ }^{* *}\right)$ e $\left({ }^{* * *}\right)$ denotam pseudo-significância estatística aos níveis de $10 \%, 5 \%$ e $1 \%$, respectivamente, construídos com base em 999 permutações aleatórias.

Em relação aos padrões espaciais relacionados a essa variável, os resultados obtidos apontam para a ocorrência de transbordamentos espaciais para os anos de 2001 e 2006 ao nível de 5\% de significância. Ao mesmo tempo, vale observar que a estatística $I$ de Moran apresentou valores positivos para todos os anos da amostra, o que demonstra que a autocorrelação seria positiva caso fosse significativa; isto é, ocorreria um padrão de transbordamento entre as localidades analisadas. 
Por outro lado, ao se analisar os efeitos transbordamento ocorridos no estado para uma amostra sem os municípios de Anchieta, Presidente Kennedy e Vitória, verifica-se a ocorrência de transbordamentos em todos os anos da amostra, uma vez que os valores do indicador $I$ de Moran assume valores superiores àquele referente ao ano de $2001^{13}$. Em termos gerais, esse resultado demonstra que resultados relacionados a padrões de crescimento para o estado do Espírito Santo podem vir a ser afetados pelo desempenho desses quatro municípios específicos, que apresentam, em geral, padrões acima da média ${ }^{14}$.

A figura 1 apresenta resultados relacionados ao diagrama de Moran para o PIB per capita dos municípios do Espírito Santo para os anos de 1999 (gráfico à esquerda) e 2007 (gráfico à direita). Cada ponto no diagrama refere-se a um município do estado, com o eixo horizontal indicando valores da variável padronizada, enquanto o eixo vertical representa a média dos municípios vizinhos em termos da mesma variável. As retas que atravessam as nuvens de pontos são obtidas através da regressão bivariada relacionando PIB per capita (PIB_PC) e seu valor defasado espacialmente ( $\left.W \_P I B \_P C\right)$.

FIGURA 1. DIAGRAMA DE DISPERSÃO DE MORAN, PIB PER CAPITA DOS MUNICÍPIOS DO ESPÍRITO SANTO, 1999 E 2007
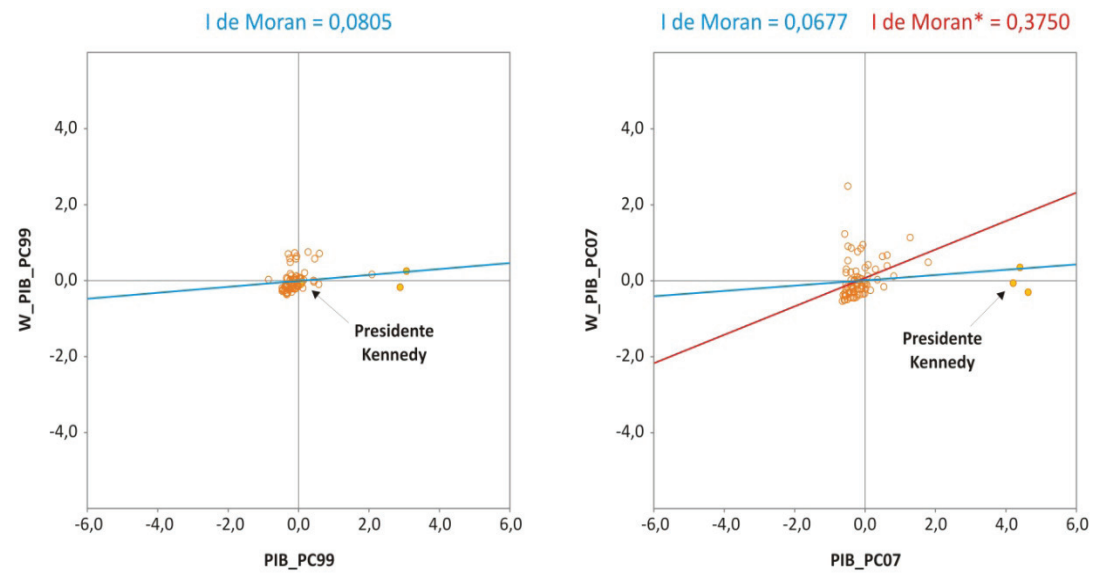

Fonte: cálculos dos autores.

13 Esses municípios foram retirados da amostra, uma vez que apresentavam padrões destoantes em relação ao resto da amostra no ano de 2007, em termos de valores de PIB per capita. Maiores detalhes adiante.

14 Análises que corroboram esse último ponto equivalem a Magalhães e Toscano (2010a) e Moulin (2010). 
Com o diagrama de Moran, percebe-se que, entre 1999 e 2007, o município de Presidente Kennedy vai se distanciando gradativamente dos demais em relação ao PIB per capita. O distanciamento desse município ocorre para a direita de forma praticamente horizontal; ou seja, seu PIB per capita ampliouse enquanto os PIB de seus vizinhos mantiveram-se relativamente estáveis. Na figura, o ponto indicado com uma seta refere-se ao município em questão.

Em 2007, percebe-se que este município se aproxima de Vitória e Anchieta, formando um grupo de outliers. De fato, a exclusão deste grupo no cálculo do I de Moran global - representado pela reta vermelha na figura 1 - implica na elevação dessa estatística de 0,07 para 0,38, com padrões de autocorrelação espacial sendo mais marcantes, neste caso.

A análise desenvolvida até o momento focou em resultados com variáveis em níveis. Mas, a possibilidade do crescimento econômico municipal ser influenciada pela vizinhança - e vice-versa - é mais forte ao se analisar sua dinâmica ao longo do tempo. Portanto, uma questão interessante a ser respondida no presente contexto equivale à seguinte: ocorreu algum padrão de transbordamento espacial em termos das taxas de crescimento dos municípios durante o período 1999-2007? A resposta a essa questão revelase como extremamente importante, uma vez que resultados de crescimento reportados anteriormente para municípios do estado (Magalhães e Toscano 2010a) podem vir a ser afetados por fatores geográficos, como a localização dos municípios em análise, por exemplo. A tabela 3 contém resultados do indicador $I$ de Moran para a taxa de crescimento do PIB per capita dos municípios, assim como para o PIB per capita setorial (agropecuária, indústria e serviços).

TABELA 3. I DE MORAN PARA TAXAS DE CRESCIMENTO DO PIB PER CAPITA, AGREGADO E SETORIAL DOS MUNICÍPIOS DO ESPÍRITO SANTO, 1999 E 2007

\begin{tabular}{l|c|c|c|c}
\hline $\begin{array}{c}\text { Taxa de } \\
\text { Crescimento do PIB }\end{array}$ & $\begin{array}{c}I \text { de } \\
\text { Moran }\end{array}$ & $\begin{array}{c}\text { Valor } \\
\text { Esperado }\end{array}$ & $\begin{array}{c}\text { Desvio } \\
\text { Padrão }\end{array}$ & Probabilidade \\
\hline PIB per capita & $0,1588^{* *}$ & $-0,016$ & 0,0693 & 0,013 \\
\hline PIB agropecuário & $0,4668^{* * *}$ & $-0,013$ & 0,0726 & 0,001 \\
\hline PIB industrial & $0,1729^{* * *}$ & $-0,015$ & 0,0676 & 0,009 \\
\hline PIB serviços & 0,0438 & $-0,014$ & 0,0659 & 0,189 \\
\hline
\end{tabular}

Fonte: cálculos dos autores.

Nota: Os termos $\left({ }^{*}\right),\left({ }^{* *}\right)$ e $\left({ }^{* *}\right)$ denotam pseudo-significância estatística a 10\%, $5 \%$ e 1\%, respectivamente, construídos com base em 999 permutações aleatórias. 
Os resultados reportados na tabela acima demonstram que ocorreram transbordamentos em termos de taxas de crescimento entre os municípios na ampla maioria das variáveis analisadas, com a exceção ficando apenas por conta do PIB per capita relacionado ao setor de serviços. Portanto, é possível dizer que municípios que tiveram um alto crescimento do PIB per capita ao longo do período analisado possuem, em média, vizinhos que também exibiram altas taxas de crescimento dessa variável. Por outro lado, de acordo com os resultados obtidos, municípios com baixas taxas de crescimento do PIB per capita possuem, em média, vizinhos com baixas taxas, também. Em última instância, esses resultados reforçam a importância de fatores geográficos na transmissão do processo de crescimento entre distintas localidades do Espírito Santo. Comparando-se os resultados em níveis e em taxas, pode-se verificar que os transbordamentos espaciais são mais intensos quando se analisa o crescimento das variáveis no tempo (taxas). De fato, a concepção de que o crescimento econômico de um município influencia os vizinhos parece mais plausível do que a concepção de que a atividade econômica em determinado instante do tempo (níveis) exerce esse papel. De fato, em termos de taxa de crescimento do PIB per capita municipal, uma informação interessante refere-se à presença de outliers na amostra, conforme destacado na figura abaixo ${ }^{15}$.

FIGURA 2. BOX MAP PARA DETECÇÃO DE OUTLIERS, TAXA DE CRESCIMENTO DO PIB PER CAPITA DOS MUNICÍPIOS DO ESPÍRITO SANTO, 1999-2007

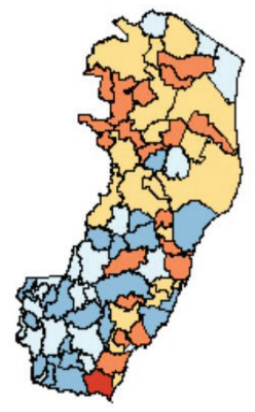

Outlier Inferior (0)

$<25 \%(19)$

$25 \%-50 \%(20)$

$50 \%-75 \%(19)$

$>75 \%$ (19)

Outlier Superior (1)

Fonte: cálculos dos autores.

Neste caso, conforme previamente notado no diagrama de dispersão de Moran, a observação que se distancia das demais refere-se ao município de Presidente Kennedy, que registrou taxas de crescimento do PIB per capita muito superiores aos demais municípios. Ademais, este mapa introduz o principal resultado que será discutido na próxima seção do trabalho: o crescimento desigual dentre localidades do estado.

15 Como critério para detecção de outliers no estado do Espírito Santo foi utilizado hinge de 3,o. Isto significa que outliers são as observações que ultrapassam em três vezes o intervalo interquartílico. 


\subsection{Testes de Autocorrelação Espacial Local}

Nesta seção são reportados resultados de testes de autocorrelação espacial local entre municípios do Espírito Santo. No caso, busca-se compreender a evolução de diferenças intermunicipais em termos de crescimento econômico com base em padrões espaciais.

A figura 3 contém resultados relacionados ao padrão de desenvolvimento espacial dos municípios do Espírito Santo, ao longo do período 1999-2007. São reportadas em cada mapa apenas áreas onde a estatística de autocorrelação espacial local - $I$ de Moran local - revelou-se como estatisticamente significativa (a um nível de 5\% de significância). Em termos das cores utilizadas nos mapas, tons em vermelho denotam localidades que podem ser caracterizadas como exibindo um padrão "alto-alto"; ou seja, localidades com altos valores de PIB per capita que estão localizadas próximas a regiões que também apresentam altos valores para essa variável. Por outro lado, tons em azul denotam localidades que exibem um padrão "baixo-baixo"; ou seja, localidades com baixos valores de PIB per capita que possuem como vizinhos municípios com baixo PIB per capita, também. Tons intermediários representam padrões alternados: "alto-baixo" (vermelho claro) e "baixo-alto" (azul claro).

\section{FIGURA 3. MAPA DE CLUSTERS PARA PIB PER CAPITA NO ESPÍRITO SANTO}

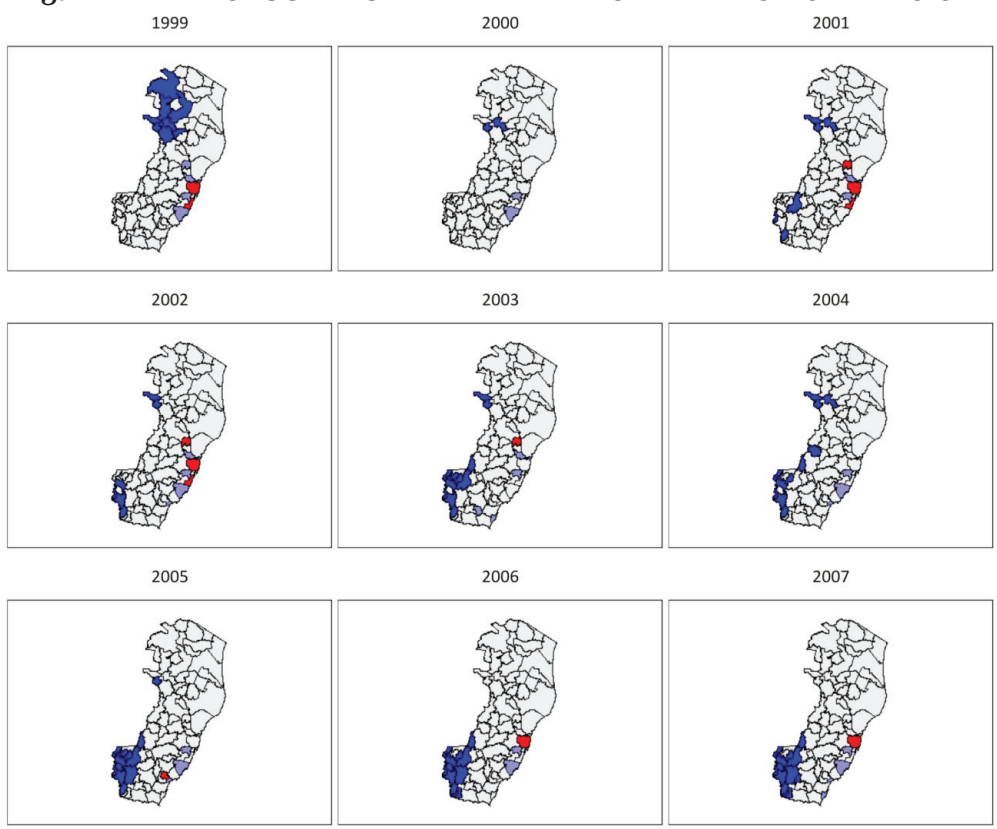

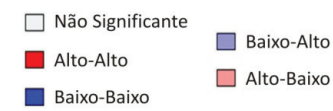

Fonte: cálculos dos autores. 
Os padrões gráficos dos mapas foram descritos ano a ano de modo a ressaltar a evolução temporal das diferenças ocorridas entre os municípios analisados. Os resultados obtidos apontam para um padrão de desenvolvimento onde municípios como Barra de São Francisco, Mantenópolis, Pancas, Alto Rio Novo, Águia Branca, São Domingos do Norte, Nova Venécia e Ecoporanga, localizados na porção noroeste do estado exibiam, em 1999, um padrão do tipo "baixo-baixo". Ou seja, os municípios pertencentes a essa área apresentavam baixos valores de PIB per capita, estando cercados por vizinhos em situação semelhante.

Por outro lado, os padrões descritos no mapa mostram que, à medida em que o tempo passa, municípios localizados na porção noroeste deixam de ter a classificação "baixo-baixo", ao mesmo tempo em que municípios localizados na porção sudoeste do estado passam a se enquadrar, aos poucos, nessa classificação. O nítido padrão observado entre 1999 e 2007 equivale ao deslocamento da faixa azul da região noroeste para a região sudoeste do estado, indicando que o agrupamento de municípios com baixo PIB per capita foi se modificando ao longo do tempo. Vale notar que, em 1999, nenhum município da região sudoeste possuía marca azul ("baixo-baixo"), que se concentrava no noroeste do estado. Aos poucos começam a surgir focos "baixo-baixo" naquela região, em um processo contínuo.

Finalmente, no ano de 2007, praticamente todo o sudoeste do estado (Brejetuba, Iúna, Apiacá, Bom Jesus do Norte, Jerônimo Monteiro, Muniz Freire, São José do Calçado, Ibitirama, Dores do Rio Preto, Guaçuí, Divino de São Lourenço e Alegre) corresponde a um cluster de baixo PIB per capita, enquanto no noroeste não existe mais nenhum sinal de padrões "baixo-baixo". Esses resultados demonstram a ocorrência de uma mudança na dinâmica de desenvolvimento dos municípios do estado, com algumas localidades do sul tendendo a apresentar um padrão de atraso relativo em relação às demais, com esse padrão sendo reforçado nos últimos anos.

Este último resultado também pode ser decomposto entre setores que compõem o PIB. As figuras 4 a 6 apresentam mapas de clusters relacionados, respectivamente, ao PIB per capita agropecuário, industrial e do setor de serviços. A intenção básica, no caso, equivale a verificar se o padrão espacial reportado para o PIB per capita total dos municípios também é confirmado no caso de medidas setoriais. Para facilitar a visualização de resultados, são expostos apenas mapas referentes aos anos de 1999 e 2007. 
FIGURA 4. MAPA DE CLUSTERS PARA PIB AGROPECUÁRIO PER CAPITA DOS MUNICÍPIOS DO ESPÍRITO SANTO, 1999 E 2007

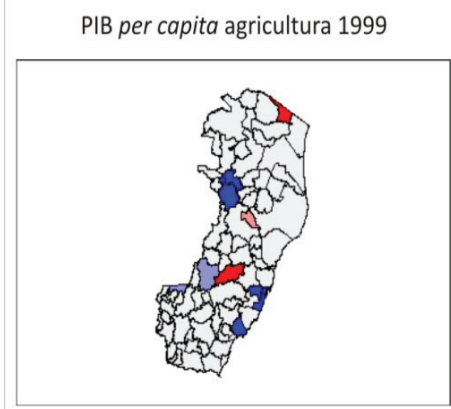

PIB per capita agricultura 2007

Fonte: cálculos dos autores.

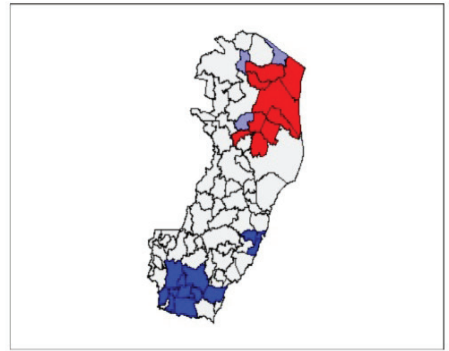

Não Significante

Alto-Alto

Baixo-Baixo

Baixo-Alto

Alto-Baixo

FIGURA 5. MAPA DE CLUSTERS PARA PIB INDUSTRIAL PER CAPITA DOS MUNICÍPIOS DO ESPÍRITO SANTO, 1999 E 2007

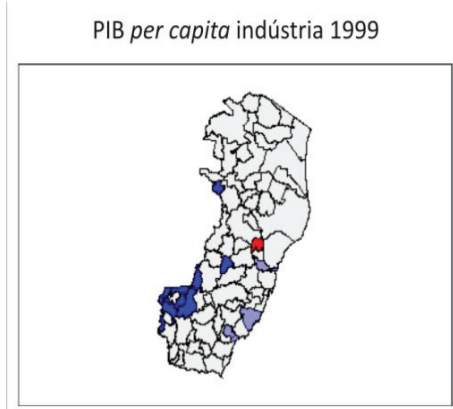

PIB per capita indústria 2007

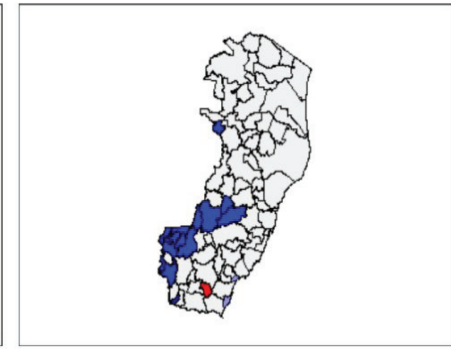

$\square$ Não Significante

$\square$ Alto-Alto

$\square$ Baixo-Baixo

Baixo-Alto

Alto-Baixo

Fonte: cálculos dos autores.

FIGURA 6. MAPA DE CLUSTERS PARA PIB DE SERVIÇOS PER CAPITA DOS MUNICÍPIOS DO ESPÍRITO SANTO, 1999 E 2007

PIB per capita serviços 1999

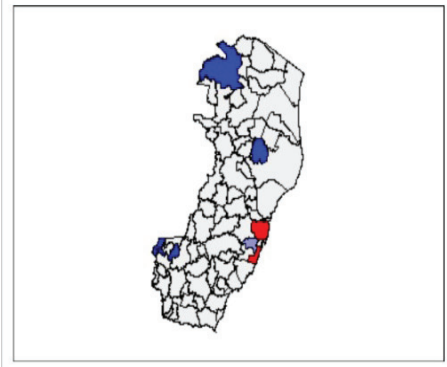

PIB per capita serviços 2007

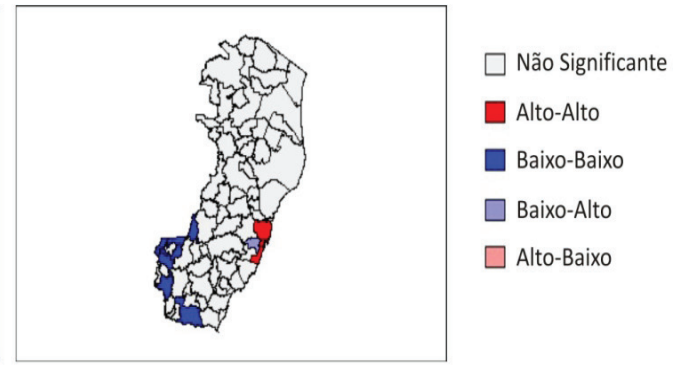

Fonte: cálculos dos autores. 
Os resultados reportados nos mapas permitem inferir a ocorrência de distintos padrões para os indicadores setoriais, embora prevaleça um padrão genérico de transbordamento entre os municípios de algumas regiões do estado.

Em relação ao PIB per capita da agropecuária, nota-se, ao longo do período 1999-2007, um fortalecimento dos municípios localizados na porção nordeste do estado, com um concomitante enfraquecimento dos municípios localizados na porção sul. Em relação ao PIB industrial, observa-se a manutenção de um padrão onde municípios localizados na porção sudoeste apresentam um padrão "baixo-baixo" no ano de 1999, com esse padrão sendo ampliado para alguns municípios vizinhos durante o ano de 2007. Por fim, em relação aos resultados referentes ao PIB do setor de serviços, nota-se um enfraquecimento de alguns municípios localizados nas porções sudoeste e sul do estado, com esse padrão tendo sido intensificado no ano de 2007. Por outro lado, em relação a essa medida setorial, é interessante notar a preponderância de municípios pertencentes à Região Metropolitana como localidades que seguem o padrão "alto-alto" nesse quesito, um resultado decorrente do próprio desenvolvimento histórico do estado, uma vez que a maioria dos serviços prestados concentrou-se originalmente na capital Vitória e em municípios vizinhos ${ }^{16}$.

A figura 7 contém mapas onde a medida empregada na análise equivale à taxa de crescimento do PIB per capita dos municípios ao longo do período 1999-2007. Neste caso, busca-se verificar a ocorrência de formação de clusters de municípios com base em seu desempenho em termos de crescimento econômico. Ou seja, os mapas em questão buscam investigar em quais regiões as taxas de crescimento (ao invés de níveis) do PIB per capita apresentaram transbordamentos entre os municípios.

16 Esse último resultado pode ser uma decorrência do fato de que, ao longo do período considerado, a maior parte da população do estado esteve concentrada na Região Metropolitana da Grande Vitória (RMGV), equivalente aos municípios de Vitória, Vila Velha, Serra e Cariacica. Ver, a esse respeito, Magalhães e Toscano (2010b). 
FIGURA7. MAPADECLUSTERSPARATAXADECRESCIMENTODOPIBPERCAPITA, AGREGADO E SETORIAL DOS MUNICÍPIOS DO ESPÍRITO SANTO, 1999-2007

Taxa de crescimento PIB per capita 1999-2007

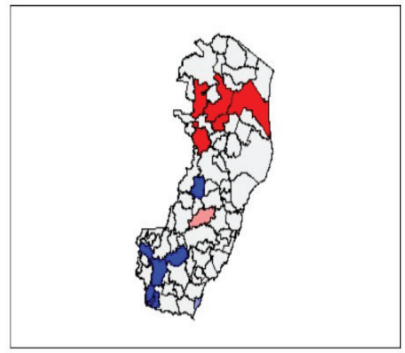

Taxa de crescimento PIB industrial per capita 1999-2007
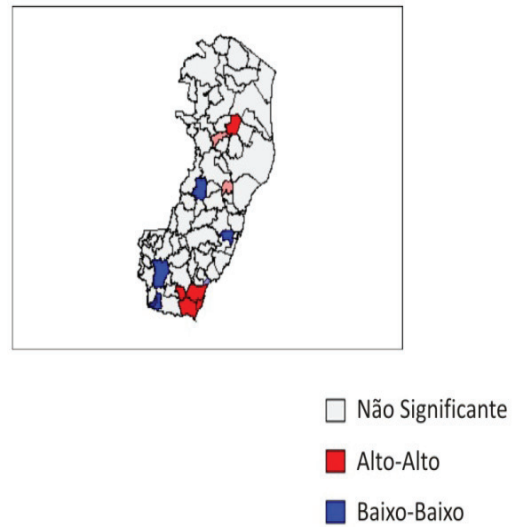

Taxa de crescimento P|B agropecuário per capita 1999-2007

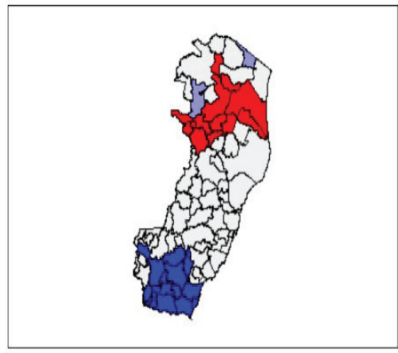

Taxa de crescimento PIB serviços per capita 1999-2007

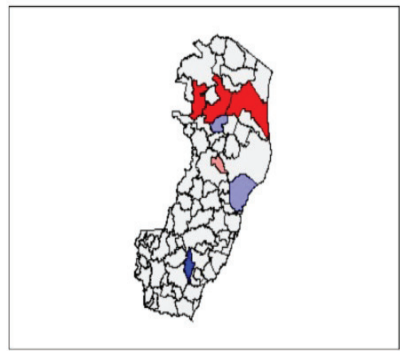

Baixo-Alto

Alto-Baixo

Fonte: cálculos dos autores.

Os resultados descritos no mapa apontam para distintos padrões de transbordamento espacial de taxas de crescimento entre municípios, que variam de acordo com o indicador considerado. Assim, em relação ao PIB per capita, nota-se a formação de clusters de municípios do tipo "alto-alto" no norte do estado (Barra de São Francisco, São Mateus, São Gabriel da Palha, Pancas e Nova Venécia), ao mesmo tempo em que nota-se a ocorrência de municípios que apresentam o padrão "baixo-baixo" na porção sudoeste (Iúna, Apiacá, Bom Jesus do Norte, Castelo, Jerônimo Monteiro, São José do Calçado, Ibitirama, Guaçuí e Alegre), um resultado em consonância com aqueles reportados para medidas de PIB per capita expressas em níveis, conforme descrito acima. 
No caso da taxa de crescimento do PIB per capita agropecuário, observa-se a clara formação de dois clusters distintos de municípios. Um primeiro grupo de municípios, localizados ao norte do estado (Jaguaré, São Mateus, São Gabriel da Palha, Mantenópolis, Pancas, Alto Rio Novo, Águia Branca, São Domingos do Norte, Vila Valério, Nova Venécia, Boa Esperança e Ponto Belo), pode ser caracterizado como exibindo um padrão "alto-alto" nesse setor.

Por outro lado, um segundo grupo de municípios localizado ao sul (Rio Novo do Sul, Itapemirim, Apiacá, Bom Jesus do Norte, Atílio Vivacqua, Vargem Alta, Cachoeiro de Itapemirim, Castelo, Jerônimo Monteiro, São José do Calçado, Ibitirama, Muqui, Presidente Kennedy, Marataízes, Alegre e Mimoso do Sul) exibe um padrão "baixo-baixo". Esses resultados demonstram que, ao longo do período analisado, municípios do norte do estado apresentaram altas taxas de crescimento no setor agropecuário, com um padrão semelhante ocorrendo para municípios vizinhos. Um padrão inverso ocorre no caso de municípios que seguem o padrão "baixo-baixo": além de terem apresentado baixas taxas de crescimento nesse setor entre os anos de 1999 e 2007, esses municípios também estiveram cercados por vizinhos que apresentaram baixas taxas de crescimento.

Embora os resultados relacionados às taxas de crescimento do PIB industrial dos municípios do estado não apresentem padrões tão marcantes quanto àqueles referentes ao setor agropecuário, chama atenção o fato de municípios localizados no extremo sul do estado (Itapemirim, Atílio Vivacqua, Presidente Kennedy e Marataízes) constituírem um cluster. Este resultado levanta evidências de que o forte crescimento do município de Presidente Kennedy, ancorado na extração petrolífera, pode ter apresentado transbordamentos para os municípios vizinhos através de um aumento da demanda por produtos industriais nestas localidades, embora esta ainda seja uma hipótese exploratória no momento ${ }^{17}$.

Em relação aos resultados relacionados às taxas de crescimento do PIB do setor de serviços dos municípios, as evidências apresentadas não confirmam os padrões descritos anteriormente, embora demonstrem a formação de um cluster de municípios ao norte do estado (São Mateus, Barra de São Francisco e Nova Venécia) que seguem o padrão “alto-alto”. Ou seja, ao longo do período de análise, esses municípios, exibiram altas taxas de crescimento do PIB per capita de serviços, ao mesmo tempo em que estavam cercados por municípios que apresentaram um padrão semelhante. Ainda em relação a esses resultados, foi observado um foco "baixo-baixo" ao sul do estado; mais especificamente, no município de Vargem Alta.

Em termos gerais, os resultados obtidos demonstram a formação de distintos clusters de municípios no Espírito Santo. Embora ocorram diferenças em termos de medidas setoriais, nota-se uma tendência de formação de clusters

Para análises relacionadas ao setor de petróleo no Espírito Santo, ver: Oliveira (2010) e Pires (2010). 
do tipo "alto-alto" no norte do estado, com concomitante surgimento de clusters do tipo "baixo-baixo" no sul, com esse resultado sendo especialmente verdadeiro no caso do setor agropecuário ${ }^{18}$.

Por fim, a figura 8 apresenta um resultado relacionado à possível ocorrência de convergência espacial de renda per capita no estado. Este mapa está relacionando a taxa de crescimento do PIB per capita dos municípios do Espírito Santo com a média do PIB per capita no ano inicial dos vizinhos. Espera-se que haja convergência espacial da renda quando municípios que apresentarem altas taxas de crescimento do PIB per capita estiverem rodeados por municípios com baixo nível de renda inicial; isto é, quando uma região pobre cresce mais rápido que as demais localidades ao seu redor ${ }^{19}$.

FIGURA 8. MAPA DE CLUSTERS BIVARIADO ENTRE TAXA DE CRESCIMENTO DO PIB PER CAPITA (1999-2007) E NÍVEL DE PIB PER CAPITA INICIAL (1999) NOS MUNICÍPIOS DO ESPÍRITO SANTO

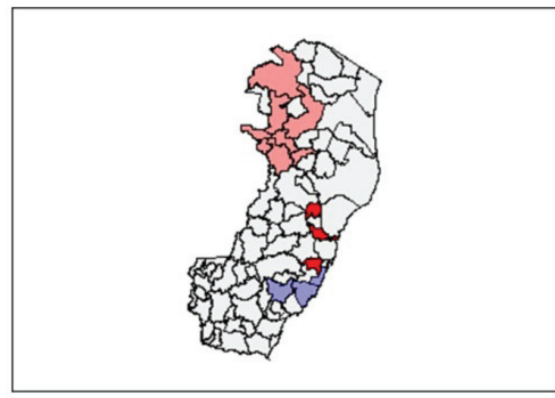

$\square$ Não Significante
$\square$ Alto-Alto
$\square$ Baixo-Baixo
$\square$ Baixo-Alto
$\square$ Alto-Baixo

Fonte: cálculos dos autores.

18 Possíveis explicações exploratórias para o surgimento de padrões empíricos nesses moldes seriam a ocorrência de armadilhas de pobreza e/ou padrões de aglomeração industrial em áreas específicas do estado. Em relação aos resultados referentes ao setor agropecuário, vale notar, conforme atentam Nonnenberg e Resende (2010, p.139) que sua evolução histórica parece estar condicionada principalmente ao desenvolvimento da cafeicultura no Espírito Santo, que ficou condicionada à região sul do estado, que possuía terras de montanha, mais propícias ao cultivo dessa lavoura.

19 Vale a ressalva de que os resultados reportados no mapa em questão representam apenas uma primeira aproximação ao tema de convergência de renda. Ver, a esse respeito, Barro e Sala-i-Martin (1995, cap.1) e Jones (2000, cap.3). Exemplos de estudos de convergência espacial aplicados ao contexto brasileiro equivalem a Almeida, Perobelli e Ferreira (2008) e Maranduba e Almeida (2009). Os autores agradecem a um parecerista anônimo por ter chamado atenção para este ponto. 
Pode ser observado um padrão de convergência na região noroeste do estado. Trata-se de municípios (Barra de São Francisco, Mantenópolis, Pancas, Alto Rio Novo, Águia Branca, São Domingos do Norte, Nova Venécia e Ecoporanga) que cresceram entre 1999 e 2007 a uma velocidade acima da média do estado e que possuíam, ao mesmo tempo, vizinhos com PIB per capita abaixo da média, no ano de 1999. Na direção oposta, as regiões Metropolitana e Metrópole Expandida Sul apresentam indícios de formação de clusters de convergência espacial negativa (padrão "baixo-alto"). Isto é, municípios como Vila Velha, Guarapari e Alfredo Chaves, ao longo do período de análise, cresceram a uma velocidade abaixo da média estadual, estando cercados por municípios vizinhos que possuíam valores de PIB per capita inicial acima da média.

Vale registrar que, dentro dessa região, o município de Cariacica cresceu a uma velocidade maior que a média, apresentando um possível padrão de divergência espacial de renda. A princípio, esses resultados são interessantes principalmente pelas sugestões que geram em termos de pesquisas relacionadas à área de Econometria Espacial, tendo os municípios do estado do Espírito Santo como unidade de análise.

\section{Testes de Robustez}

Nesta seção são reportados resultados de testes realizados para checar a robustez dos principais resultados obtidos acima. Basicamente, são conduzidos três testes de robustez: um primeiro teste, relacionado à escolha específica da matriz de pesos espaciais; um segundo teste, relacionado à ordem de vizinhança dos municípios analisados e seus impactos sobre o comportamento da estatística LISA; e um terceiro, relacionado à importância de transbordamentos associados a áreas fronteiriças do estado.

\subsection{Escolha da Matriz de Pesos Espaciais}

Em termos gerais, os resultados da AEDE podem ser sensíveis à escolha da matriz de pesos espaciais. Para verificar a robustez dos resultados, alguns trabalhos, como Perobelli e Haddad (2006) e Perobelli et al. (2007), apresentam a matriz de transição de probabilidades, que verifica a estabilidade espacial do I de Moran local ao se modificar o número de vizinhos das unidades espaciais.

A lógica desses testes é a seguinte: parte-se de uma matriz inicial com $\mathrm{k}$ vizinhos; depois, modifica-se o número de vizinhos para $\mathrm{k}^{\prime} \neq \mathrm{k}$ e $\mathrm{k} " \neq \mathrm{k}$, procurando-se verificar se os resultados obtidos se mantém estáveis ${ }^{20}$.

20 Em Perobelli et al. (2007), os autores partem de uma matriz de vizinhança com 10 vizinhos e fazem a transição para $k^{\prime}=15$ e $k^{\prime \prime}=20$. Já Perobelli e Haddad (2006) utilizam uma matriz inicial com $k=5$ e realizam a análise de robustez com a modificação para 3 e 4 vizinhos. 
Resultados mais robustos serão aqueles onde não se altera a situação inicial, independentemente do número escolhido de vizinhos. $\mathrm{Na}$ prática, quanto mais próxima de 100 for a diagonal principal da matriz de transição de probabilidades, mais robustos serão os resultados ${ }^{21}$.

Uma vez que foi utilizada uma matriz de vizinhança de contiguidade de primeira ordem, admitiu-se que o conjunto vizinhança de cada município difere de acordo com o número de vizinhos com fronteira comum: no caso, este conjunto variou entre dois e dez vizinhos. Por conta disso, fazer um teste de robustez transformando a matriz de vizinhança utilizada em uma matriz de $\mathrm{k}$ vizinhos implica reduzir o número de vizinhos para alguns e aumentar para outros, caso $\mathrm{k}<10$. Tendo em vista essa questão, construiu-se duas matrizes de transição de probabilidades para taxa de crescimento do PIB per capita 19992007, ao nível de significância de 5\%, considerando as seguintes transições: matriz rainha para 3 ou 4 vizinhos mais próximos de cada município ${ }^{22}$.

A tabela 4 contém os resultados desses experimentos.

TABELA 4. ANÁLISE DE ROBUSTEZ DO I DE MORAN LOCAL PARA TAXA DE CRESCIMENTO DO PIB PER CAPITA, 1999-2007

\section{Transição I: Rainha (linha) para 3 vizinhos (coluna)}

\begin{tabular}{c|c|c|c|c|c}
\hline \multicolumn{6}{c}{ Rainha à K3 } \\
\hline & NS & AA & BB & BA & AB \\
\hline NS & 93,5 & 1,6 & 3,2 & 1,6 & 0,0 \\
\hline AA & 0,0 & 100,0 & 0,0 & 0,0 & 0,0 \\
\hline BB & 75,0 & 0,0 & 25,0 & 0,0 & 0,0 \\
\hline BA & 0,0 & 0,0 & 0,0 & 100,0 & 0,0 \\
\hline AB & 0,0 & 0,0 & 0,0 & 0,0 & 100,0 \\
\hline \multicolumn{7}{|c|}{ Transição II: Rainha (linha) para 4 vizinhos (coluna) } \\
\hline \multicolumn{7}{|c|}{ Rainha à K4 } \\
\hline NS & 90,3 & 3,2 & 1,6 & 1,6 & 3,2 \\
\hline AA & 40,0 & 60,0 & 0,0 & 0,0 & 0,0 \\
\hline BB & 75,0 & 0,0 & 25,0 & 0,0 & 0,0 \\
\hline BA & 0,0 & 0,0 & 0,0 & 100,0 & 0,0 \\
\hline AB & 50,0 & 0,0 & 0,0 & 0,0 & 50,0 \\
\hline
\end{tabular}

Fonte: cálculos dos autores.

Nota: os termos "NS", "AA", "BB", "BA" e "AB” denotam, respectivamente, os padrões "não-significante", "alto-alto", "baixo-baixo", "baixo-alto" e "alto-baixo".

21 Vale a ressalva de que esses estudos partem de uma matriz onde todas as unidades espaciais possuem o mesmo número $k$ de vizinhos. Portanto, a transformação de $k$ em $k$ ' e depois em $k$ " aumenta o conjunto vizinhança de todas as unidades espaciais de forma homogênea.

22 Para construir as matrizes de $k$ vizinhos mais próximos, as distâncias entre os municípios foram calculadas com base nos grandes círculos entre os centróides dos polígonos municipais, em moldes semelhantes a Le Gallo e Ertur (2003), Perobelli e Haddad (2006) e Perobelli et al. (2007). 
A partir da análise desenvolvida, pode-se inferir que os resultados obtidos anteriormente são robustos na medida em que os valores da diagonal principal se aproximam de 100 na maioria dos casos considerados. Este resultado se comprova na medida em que as únicas alterações de categoria - isto é, onde os valores da diagonal principal não igualam 100 - ocorreram de um grupo com significância estatística para o grupo não significante, provavelmente em decorrência da redução de tamanho do conjunto vizinhança de alguns municípios. Em síntese, a mudança de matriz de defasagem espacial não contradiz o resultado inicial.

\subsection{Ordem de Vizinhança dos Municípios}

Outra possibilidade de inferir sobre a robustez dos resultados obtidos equivale a verificar como a estatística LISA se comporta alterando-se a ordem de vizinhança. Neste caso, na matriz de contiguidade de $2^{\mathrm{a}}$ ordem considerase dentro do conjunto vizinhança de cada município os vizinhos diretos e seus vizinhos. Já no caso de uma matriz de $3^{\mathrm{a}}$ ordem, consideram-se os vizinhos, seus vizinhos e os vizinhos dessas localidades. Espera-se que a utilização dessas matrizes mantenha qualitativamente os resultados obtidos anteriormente, podendo-se assim concluir que são robustos. PIB PER CAPITA 1999-2007 DE ACORDO COM MATRIZES DE CONTIGUIDADE RAINHA DE $1^{\mathrm{a}}, 2^{\mathrm{a}} \mathrm{E} 3^{\mathrm{a}}$ ORDEM
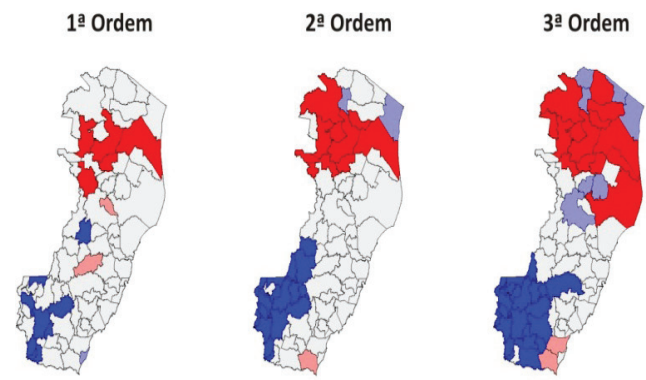

$\square$ Não Significante

$\square$ Alto-Alto

Baixo-Baixo

Baixo-Alto

Alto-Baixo

Fonte: cálculos dos autores. 
Pelos resultados obtidos na figura 9, percebe-se que a ampliação do conjunto vizinhança de cada município implica no aumento da quantidade de municípios com I de Moran local significativo. Interessante notar que variações nos conjuntos vizinhança dos municípios do estado tende, na verdade, a intensificar os padrões de transbordamento espacial supracitados. Em última instância, esse resultado tende a acentuar a robustez dos resultados obtidos anteriormente.

\subsection{Importância de Áreas Fronteiriças}

Um terceiro teste de robustez que pode ser realizado no presente contexto equivale a verificar a ocorrência de transbordamentos espaciais em regiões fronteiriças do Espírito Santo, dado o fato de que o estado faz fronteira com os estados da Bahia, Minas Gerais e Rio de Janeiro. A figura 10 expõe os resultados desse experimento, no caso de taxas de crescimento do PIB per capita dos municípios. No caso, o mapa do Espírito Santo aparece em destaque na figura (em amarelo) ${ }^{23}$.

\section{FIGURA 10. ROBUSTEZ: TRANSBORDAMENTOS ESPACIAIS EM ÁREAS FRONTEIRIÇAS DO ESTADO DO ESPÍRITO SANTO}

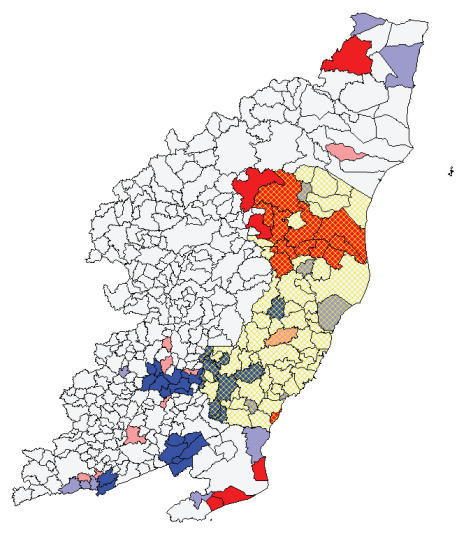

Fonte: cálculos dos autores.

23 Os autores agradecem a um parecerista anônimo por ter chamado atenção para esse ponto. Para uma análise da influência de regiões fronteiriças no estado, com ênfase em indicadores de pobreza e desigualdade, ver: Leite e Silva (2011). 
Os resultados descritos na figura permitem constatar a ocorrência de transbordamentos espaciais em algumas localidades situadas em áreas fronteiriças do estado e que tendem a reforçar os resultados acima. Especificamente, nota-se a vigência de um padrão "alto-alto" em alguns municípios do estado de Minas Gerais que fazem fronteira ao norte do Espírito Santo, bem como padrões "baixo-baixo" e "alto-baixo" no caso de municípios que fazem fronteira ao sul.

A princípio, esses resultados, poderiam vir a auxiliar na explicação da atual configuração de transbordamentos espaciais no Espírito Santo, embora ainda sejam necessários esforços de pesquisa adicionais nesse sentido (maiores detalhes adiante). De qualquer forma, os resultados obtidos chamam atenção para a possibilidade de padrões de difusão espacial entre municípios de distintos estados, ao mesmo tempo em que confirmam os resultados inicialmente reportados.

\section{Conclusões e Agenda de Pesquisa}

O presente trabalho propôs-se a apresentar uma caracterização empírica inicial relacionada ao surgimento de diferenças espaciais em termos da evolução dos PIB per capita dos municípios do Espírito Santo, bem como a consolidação dessas diferenças ao longo do tempo.

Os principais resultados obtidos foram os seguintes:

(i) Há indícios de ocorrência de transbordamentos espaciais entre os municípios do Espírito Santo, com esse resultado sendo reforçado no caso de amostras que não consideram municípios com padrões destoantes do restante do estado.

(ii) Resultados relacionados à formação de clusters de municípios apontam para nítidas diferenças entre municípios localizados ao norte e ao sul do estado do Espírito Santo.

(iii) Ao longo do período 1999-2007, vem ocorrendo um padrão de crescimento onde municípios na porção noroeste do estado tendem, em média, a crescer mais do que municípios localizados na porção sudoeste.

Os resultados obtidos demonstram que, ao longo do período de análise considerado, surgiram diferenças entre as regiões norte e sul do estado, com essas diferenças sendo fortalecidas nos últimos anos. Especificamente, os resultados demonstram claramente a consolidação dessas diferenças entre as regiões do estado com o passar do tempo, com municípios da região noroeste apresentando um crescimento econômico superior aos municípios da região sudoeste. 
Esses resultados são importantes no sentido de equivalerem a um primeiro registro de disparidades ocorridas entre os municípios do Espírito Santo ao longo da dimensão espacial. Análises mais detalhadas serão necessárias no sentido de se investigar novos padrões espaciais de desenvolvimento regional que possam vir a ocorrer no estado. Nesse sentido, fica a sugestão de elaboração de estudos baseados em técnicas de Econometria Espacial, nos moldes propostos por Anselin (1988) ou LeSage (1999), por exemplo, que podem ser úteis no sentido de verificação de novos padrões de crescimento regional relacionados às distintas localidades do Espírito Santo.

Outra sugestão de pesquisa seria relacionada à avaliação de instituições voltadas para a promoção do desenvolvimento de localidades específicas no estado. Por exemplo, a avaliação de fundos constitucionais regionais, nos moldes propostos por Silva, Resende e Silveira Neto (2009), pode vir a revelar a ocorrência de vantagens associadas ao crescimento e desenvolvimento de alguns municípios do estado. O entendimento dos mecanismos subjacentes a esse processo pode constituir fator fundamental à compreensão das diferenças existentes entre essas localidades supracitadas.

Mais importante ainda pode ser a explicação das causas desse processo de desenvolvimento desigual. Por um lado, existem evidências de nítidas diferenças nos padrões de crescimento dos municípios e microrregiões do Espírito Santo (Magalhães e Toscano, 2010a); por outro, há autores que associam o desenvolvimento ocorrido no estado com um processo de "modernização conservadora" onde, apesar de ter ocorrido um padrão de diversificação da estrutura econômica local, ainda prevalece um alto grau de concentração setorial, com ênfase na produção de commodities (Caçador e Grassi, 2009a,b; Oliveira, Villaschi Filho e Felipe, 2010)24. Uma possível decorrência desses processos seria a formação de uma configuração espacial nos moldes existentes atualmente, embora esta seja uma hipótese exploratória no momento ${ }^{25}$.

Em termos de políticas públicas, os resultados reportados neste trabalho chamam atenção para a necessidade de formulação e implementação de políticas voltadas para dois aspectos distintos. Em primeiro lugar, faz-se necessário o fortalecimento econômico dos municípios do interior do estado, nos moldes da política de "interiorização do desenvolvimento", conforme preconizado no plano de desenvolvimento de longo prazo do governo estadual (ES, 2025) (SEP, 2006). Em segundo lugar, devem ser pensadas estratégias específicas de desenvolvimento dos municípios do estado, com especial ênfase naqueles localizados na porção sudoeste, dados os padrões aqui reportados.

24 Para uma análise da importância empírica de variações em preços de commodities sobre o nível de atividade da economia espírito santense, ver: Magalhães (2011).

25 Uma evidência preliminar favorável a essa hipótese equivale a resultados relacionados ao Zoneamento Ecológico Econômico do Espírito Santo (ZEE-ES 2010), que apontam para uma configuração espacial onde a porção sudoeste do estado apresenta resultados de potencial social e vulnerabilidade natural inferiores àqueles referentes à porção noroeste. 
Em particular, a intervenção governamental pode vir a ser fundamental ao desenvolvimento desses municípios, uma vez que estes se encontram em uma situação de baixo crescimento, sendo simultaneamente cercados por municípios em situações similares.

Em termos gerais, o presente trabalho equivale a uma tentativa inicial no sentido de identificar as principais desigualdades intraestaduais vigentes no Espírito Santo, com ênfase nas diferenças entre as regiões norte e sul do estado. Espera-se que a pesquisa futura venha a descobrir novos padrões empíricos relacionados ao tema que possam ser úteis na formulação e implementação de políticas públicas voltadas à redução das desigualdades existentes entre os municípios de um mesmo estado.

\section{Referências bibliográficas}

ALMEIDA, E. S. (2009). Análise exploratória de dados espaciais. Faculdade de Economia e Administração da Universidade Federal de Juiz de Fora (UFJF).

ALMEIDA, E. S. \& PEROBELLI, F. S. \& FERREIRA, P. (2008). "Existe convergência espacial da produtividade agrícola no Brasil?" Revista de Economia e Sociologia Rural, vol. 46 (1), p. 31-52.

ANSELIN, L. (1988). Spatial Econometrics: methods and models. Boston: Kluwer Academic.

ANSELIN, L. (1993). "The Moran scatterplot as an ESDA tool to assess local instability in spatial association”. Regional Research Institute of West Virginia University, Research Paper, n. ${ }^{\circ}$ 9330. URL [on-line]: <http://www.rri.wvu.edu/pdffiles/wp9330.pdf>. Acesso em: 26/11/2010.

ANSELIN, L. (1995). "Local indicators of spatial association - LISA". Geographical Analysis, vol. 27 (2), p. 93-115.

ANSELIN, L.; SRIDHARAM, S.; GHOLSTON, S. (2007). "Using exploratory spatial data analysis to leverage social indicator databases: the discovery of interesting patterns". Social Indicators Research, vol. 82 (2). URL [on-line]: <http://www.chs.med.ed.ac.uk/ruhbc/evaluation/key_ capability_store/social_indicators_FINAL.pdf $>$. Acesso em: 09/2010.

BARRO, R.J.; SALA-I-MARTIN, X. (1995). Economic Growth. McGraw-Hill.

BARROS, R. P. et al. (2010). "Pobreza no Espírito Santo". In: VESCOVI, A. P. V. \& BONELLI, R. [orgs.]. Espírito Santo: instituições, desenvolvimento e inclusão social. Vitória: IJSN. 
BONELLI, R. \& LEVY, P. M. (2010). D”eterminantes do crescimento econômico do Espírito Santo: uma análise de longo prazo”. In: VESCOVI, A. P. V. \& BONELLI, R. [orgs.]. Espírito Santo: instituições, desenvolvimento e inclusão social. Vitória: IJSN.

CAÇADOR, S. B. \& GRASSI, R. A. (2009a). “A evolução recente da economia do Espírito Santo: um estado desenvolvido ou periférico?” In: Anais do XXXVII Encontro Nacional de Economia. Foz do Iguaçu, 2009.

CAÇADOR, S. B. \& GRASSI, R. A. (2009b). “Olhar crítico sobre o desempenho recente da economia capixaba: uma análise a partir da literatura de desenvolvimento regional e de indicadores de inovação”. Revista Econômica do Nordeste, vol. 40 (3), p. 453-480, jul.-set.2009.

JONES, C. I. (2000). Introdução à teoria do crescimento econômico. $2^{\mathrm{a}}$ ed. Rio de Janeiro: Campus.

LE GALLO, J. \& ERTUR, C. (2003). "Exploratory spatial data analysis of the distribution of regional per capita GDP in Europe, 1980-1995". Papers in Regional Science, vol. 82(2), p. 175-201.

LEITE, L. M.; MAGALHÃES, M. A. (2010). “Transbordamentos espaciais nos municípios do Espírito Santo”. Texto para Discussão, 19, IJSN. URL [on-line]: <http://www.ijsn.es.gov.br/attachments/760_ijsn_td19.pdf>. Acesso em: 22/12/2010.

LEITE, L. M. \& SILVA, P. S. (2011). "Evidências de transbordamento da pobreza e da concentração de renda entre os municípios do Espírito Santo e seus vizinhos em outros estados". Texto para Discussão, n. ${ }^{\circ}$ 25, IJSN. URL [on-line]: <http://www.ijsn.es.gov.br/attachments/854_ijsn_td25_.pdf>. Acesso em: 06/05/2011.

LESAGE, J. P. (1999). The theory and practice of spatial econometrics. Departament of Economics, University of Toledo [manuscrito], fev. 1999. URL [on-line]: <http://www.spatial-econometrics.com/html/wbook.pdf>. Acesso em: 16/09/2010.

LÓPEZ, M. V. (2007). "Heterogeneidad espacial, convergencia y crescimiento regional em Mexico”. In: Anais do XVII Coloquio de Economía Matemática y Econometría, Universidad de Quintana Roo. URL [on-line]: <http://www.dcsea. uqroo.mx/fwalla/Ponencias_Coloquio/ponencia\%20Valdivia.pdf $>$. Acesso em 02/09/2010.

MAGALHÃES, M. A. (2011). Preços de commodities e nível de atividade em uma pequena economia aberta: evidências empíricas para o estado do Espírito Santo. Economia e Sociedade, 2011. [no prelo] 
MAGAlHÃES, M. A. \& TOSCANO, V. N. (2010a). “Crescimento econômico e bem-estar nos municípios do Espírito Santo”. Texto para Discussão, 15, IJSN. URL [on-line]: <http://www.ijsn.es.gov.br/attachments/656_ijsn_td15.pdf> . Acesso em: 25/09/2010.

MAGALHÃES, M. A. \& TOSCANO, V. N. (2010b). "Hierarquia urbana no Espírito Santo”. Nota Técnica, n. ${ }^{0}$ 11, IJSN. URL [on-line]: < http://www.ijsn.es.gov.br/ attachments/694_ijsn_nt11.pdf >. Acesso em: 02/10/2010.

MAGALHÃES, M. A. \& TOSCANO, V. N. (2011). "Medindo a concentração de investimentos regionais: o caso do estado do Espírito Santo". Planejamento e Políticas Públicas, n. ${ }^{\circ}$ 36, jun. 2011. [no prelo]

MARANDUBA, N. G. Jr. \& ALMEIDA, E. S. (2009). “Análise de convergência espacial dos repasses da lei Robin Hood”. Economia e Sociedade, vol. 18 (3), p. 583-601.

MESSNER, S. et. al. (1999). "The spatial patterning of county homicide rates: an application of exploratory spatial data analysis". Journal of Quantitative Criminology, vol. 15 (4), p.423-450.

MORAN, P. A .P. (1948) "The interpretation of statistical maps". Journal of the Royal Statistical Society, vol. 10 (2), p. 243-251.

MOULIN, C. D. (2010). Produto Interno dos Municípios do Espírito Santo: 2008. IJSN, abr. 2010. [manuscrito]

NONNENBERG, M. J. B. \& RESENDE, G. C. (2010). "Desenvolvimento da agropecuária do Espírito Santo”. In: VESCOVI, A. P. V. \& BONELLI, R. [orgs.]. Espírito Santo: instituições, desenvolvimento e inclusão social. Vitória: IJSN.

OLIVEIRA, A. (2010). "Petróleo e desenvolvimento: oportunidades e desafios para o Espírito Santo”. In: VESCOVI, A. P. V. \& BONELLI, R. [orgs.]. Espírito Santo: instituições, desenvolvimento e inclusão social. Vitória: IJSN.

OLIVEIRA, U. J. \& VILLASCHI FILHO, A. \& FELIPE, E. S. (2010). “Diversificação econômica e a consolidação de uma estrutura industrial e urbana: alguns aspectos da economia capixaba nos anos 1980-200o”. In: Anais do I Encontro de Economia do Espírito Santo, Vitória, 2010.

PEROBELLI, F. S. \& HADDAD, E. A. (2006). "Padrões de comércio interestadual no Brasil, 1985 e 1997”. Revista de Economia Contemporânea, vol. 10 (1).

PEROBELli, F. S. \& ALMEIDA, E. S. \& ALVIM, M. I. \& FERREIRA, P. G. (2007). "Produtividade do setor agrícola brasileiro (1991-2003): uma análise espacial." Nova Economia, vol. 17 (1), p. 65-91.

PIMENTEL, E. A. \& HADDAD, E. A. (2004). “Análise da distribuição espacial da renda no estado de Minas Gerais: uma abordagem setorial”. TD Nereus n. ${ }^{\circ}$ 02/2004, FEA-USP. URL [on-line]: <http://www.usp.br/feaecon/media/livros/ file_514.pdf $>$ Acesso em: 22/12/2010. 
PIRES, A. (2010). “A indústria do petróleo e o caso do Espírito Santo”. In: VESCOVI, A. P. V. \& BONELLI, R. [orgs.]. Espírito Santo: instituições, desenvolvimento e inclusão social. Vitória: IJSN.

SECRETARIA DE ESTADO DE ECONOMIA E PLANEJAMENTO (2006). Plano de Desenvolvimento Espírito Santo 2025 (ES 2025): Avaliação Estratégica do Espírito Santo e Elementos para a Visão de Futuro. URL [on-line]: <http:// www.espiritosanto2025.com.br>. Acesso em: 10/01/2011.

SILVA, A. M. A. \& RESENDE, G. M. \& SILVEIRA NETO, R. M. (2009). "Eficácia do gasto público: uma avaliação do FNE, FNO e FCO”. Estudos Econômicos, vol. 39 (1), p.89-125.

TAVEIRA, A. M. A. et al. (2010). Investimentos Previstos para o Espírito Santo: 2009-2014. Instituto Jones dos Santos Neves (IJSN). URL [on-line]: <http:// www.ijsn.es.gov.br/attachments/625_INVESTIMENTOS\%202009-2014.pdf>. Acesso em: 09/11/2010.

TYSZLER, M. (2006). Econometria espacial: discutindo medidas para a matriz de ponderação espacial. [dissertação de mestrado]. Escola de Administração de Empresas de São Paulo da Fundação Getúlio Vargas (FGV).

VESCOVI, A. P. V. J. \& CASTRO, M. W. (2008). “A evolução recente da classe média no Espírito Santo”. Nota Técnica, n. ${ }^{\circ}$ 02, IJSN. URL [on-line]: <http://www. ijsn.es.gov.br/attachments/120_NT-02-2008.pdf>. Acesso em: 08/11/2010.

ZONEAMENTO ECOLÓGICO-ECONÔMICO DO ESTADO DO ESPÍRITO SANTO [ZEE-ES] (2010). Sumário Executivo. Instituto Estadual de Meio Ambiente e Recursos Hídricos do Espírito Santo (IEMA).

Recebido em: 04 de outubro de 2010 Primeira resposta em: 04 de novembro de 2010 Aceite em: 17 de maio de 2011 


\section{Informações socioeconômicas sobre o Estado do Espírito Santo}

O Estado do Espírito Santo encontra-se atualmente dividido em 78 municípios. No caso de algumas análises relacionadas a políticas públicas, o estado costuma ser dividido em 4 (quatro) macrorregiões de planejamento ou em 12 (doze) microrregiões administrativas.

A Tabela A1 contém uma lista dos municípios que compõem as regiões supracitadas, enquanto que as figuras A1 e A2 contem mapas expondo a divisão do Estado nas macrorregiões de planejamento e nas microrregiões administrativas, respectivamente.

TABELA A1. MACRORREGIÕES DE PLANEJAMENTO E MICRORREGIÕES DE GESTÃO ADMINISTRATIVA DO ESTADO DO ESPÍRITO SANTO

\begin{tabular}{|c|c|c|}
\hline Macrorregião & Microregião & Município \\
\hline \multirow{19}{*}{ Metropolitana } & \multirow{6}{*}{ Central Serrana } & Itaguaçu \\
\hline & & Itarana \\
\hline & & Santa Leopoldina \\
\hline & & Santa Maria de Jetibá \\
\hline & & Santa Teresa \\
\hline & & São Roque do Canaã \\
\hline & \multirow{6}{*}{ Metrópole Expandida Sul } & Alfredo Chaves \\
\hline & & Anchieta \\
\hline & & Iconha \\
\hline & & Itapemirim \\
\hline & & Marataízes \\
\hline & & Piúma \\
\hline & \multirow{7}{*}{ Metropolitana } & Cariacica \\
\hline & & Fundão \\
\hline & & Guarapari \\
\hline & & Serra \\
\hline & & Viana \\
\hline & & Vila Velha \\
\hline & & Vitória \\
\hline
\end{tabular}


LEITE, M. L.; MAGALHÃES, M. A. Desigualdades intrasetoriais no Espirito Santo...

TABELA A1 (continuação). MACRORREGIÕES DE PLANEJAMENTO E MICRORREGIÕES DE GESTÃO ADMINISTRATIVA DO ESPÍRITO SANTO

\begin{tabular}{|c|c|c|}
\hline \multirow{13}{*}{ Metropolitana } & \multirow{6}{*}{ Pólo Linhares } & Aracruz \\
\hline & & Ibiraçu \\
\hline & & João Neiva \\
\hline & & Linhares \\
\hline & & Rio Bananal \\
\hline & & Sooretama \\
\hline & \multirow{7}{*}{ Sudoeste Serrana } & Afonso Cláudio \\
\hline & & Brejetuba \\
\hline & & Conceição do Castelo \\
\hline & & Domingos Martins \\
\hline & & Laranja da Terra \\
\hline & & Marechal Floriano \\
\hline & & Venda Nova do Imigrante \\
\hline \multirow{17}{*}{ Noroeste } & \multirow{5}{*}{ Noroeste I } & Água Doce do Norte \\
\hline & & Barra de São Francisco \\
\hline & & Ecoporanga \\
\hline & & Mantenópolis \\
\hline & & Vila Pavão \\
\hline & \multirow{6}{*}{ Noroeste II } & Águia Branca \\
\hline & & Boa Esperança \\
\hline & & Nova Venécia \\
\hline & & São Domingos do Norte \\
\hline & & São Gabriel da Palha \\
\hline & & Vila Valério \\
\hline & \multirow{6}{*}{ Pólo Colatina } & Alto Rio Novo \\
\hline & & Baixo Guandu \\
\hline & & Colatina \\
\hline & & Governador Lindenberg \\
\hline & & Marilândia \\
\hline & & Pancas \\
\hline
\end{tabular}


LEITE, M. L.; MAGALHÃES, M. A. Desigualdades intrasetoriais no Espirito Santo...

\begin{tabular}{|c|c|c|}
\hline \multirow{8}{*}{ Norte } & \multirow{4}{*}{ Extremo Norte } & Montanha \\
\hline & & Mucurici \\
\hline & & Pinheiros \\
\hline & & Ponto Belo \\
\hline & \multirow{4}{*}{ Litoral Norte } & Conceição da Barra \\
\hline & & Jaguaré \\
\hline & & Pedro Canário \\
\hline & & São Mateus \\
\hline \multirow{21}{*}{ Sul } & \multirow{10}{*}{ Caparaó } & Alegre \\
\hline & & Divino de São Lourenço \\
\hline & & Dores do Rio Preto \\
\hline & & Guaçuí \\
\hline & & Ibatiba \\
\hline & & Ibitirama \\
\hline & & Irupi \\
\hline & & Iúna \\
\hline & & Muniz Freire \\
\hline & & São José do Calçado \\
\hline & \multirow{11}{*}{ Pólo Cachoeiro } & Apiacá \\
\hline & & Atilio Vivacqua \\
\hline & & Bom Jesus do Norte \\
\hline & & Cachoeiro de Itapemirim \\
\hline & & Castelo \\
\hline & & Jerônimo Monteiro \\
\hline & & Mimoso do Sul \\
\hline & & Muqui \\
\hline & & Presidente Kennedy \\
\hline & & Rio Novo do Sul \\
\hline & & Vargem Alta \\
\hline
\end{tabular}




\section{FIGURA A1. MACRORREGIÕES DE PLANEJAMENTO DO ESPÍRITO SANTO}

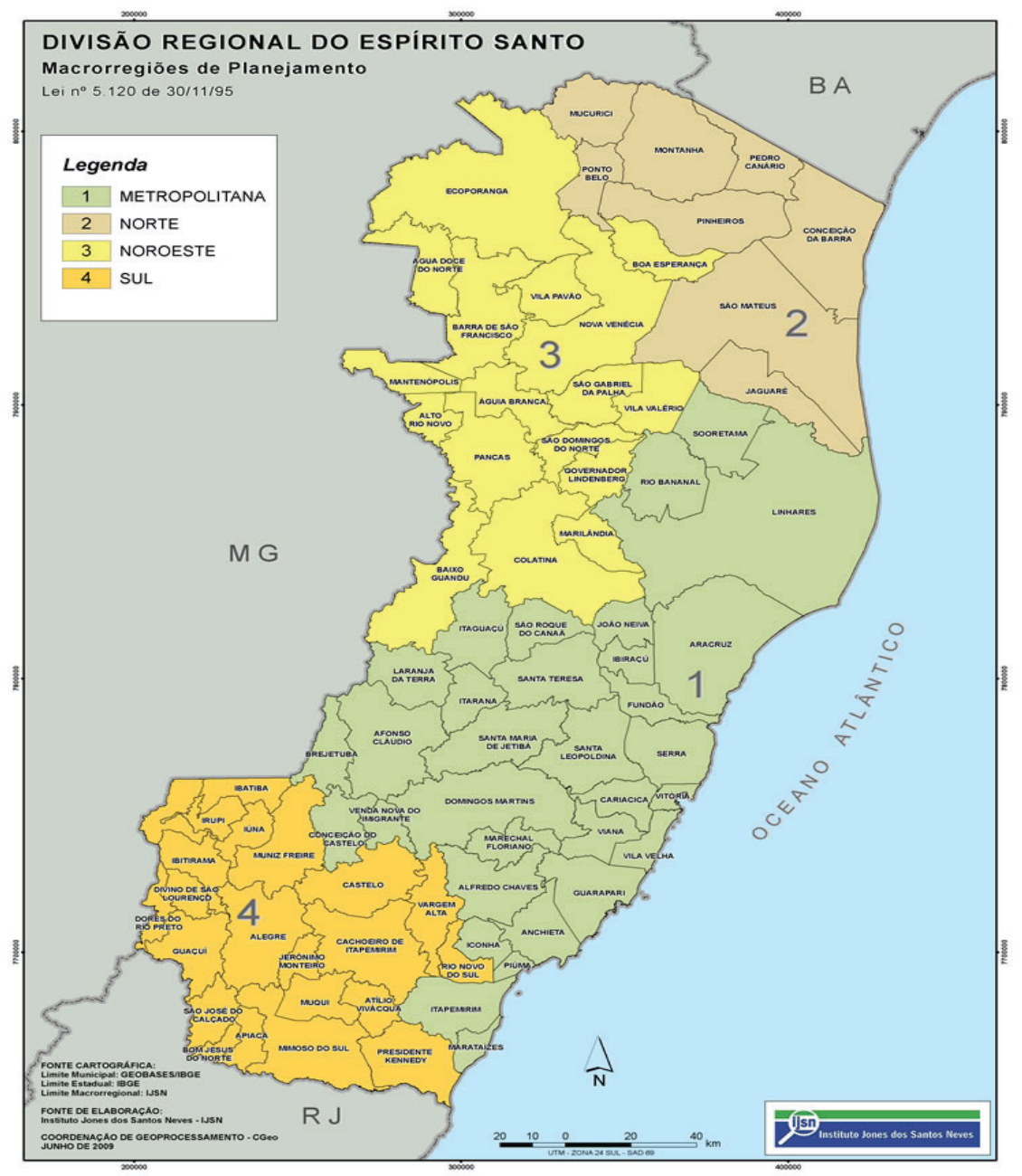




\section{FIGURA A2. MICRORREGIÕES ADMINISTRATIVAS DO ESPÍRITO SANTO}

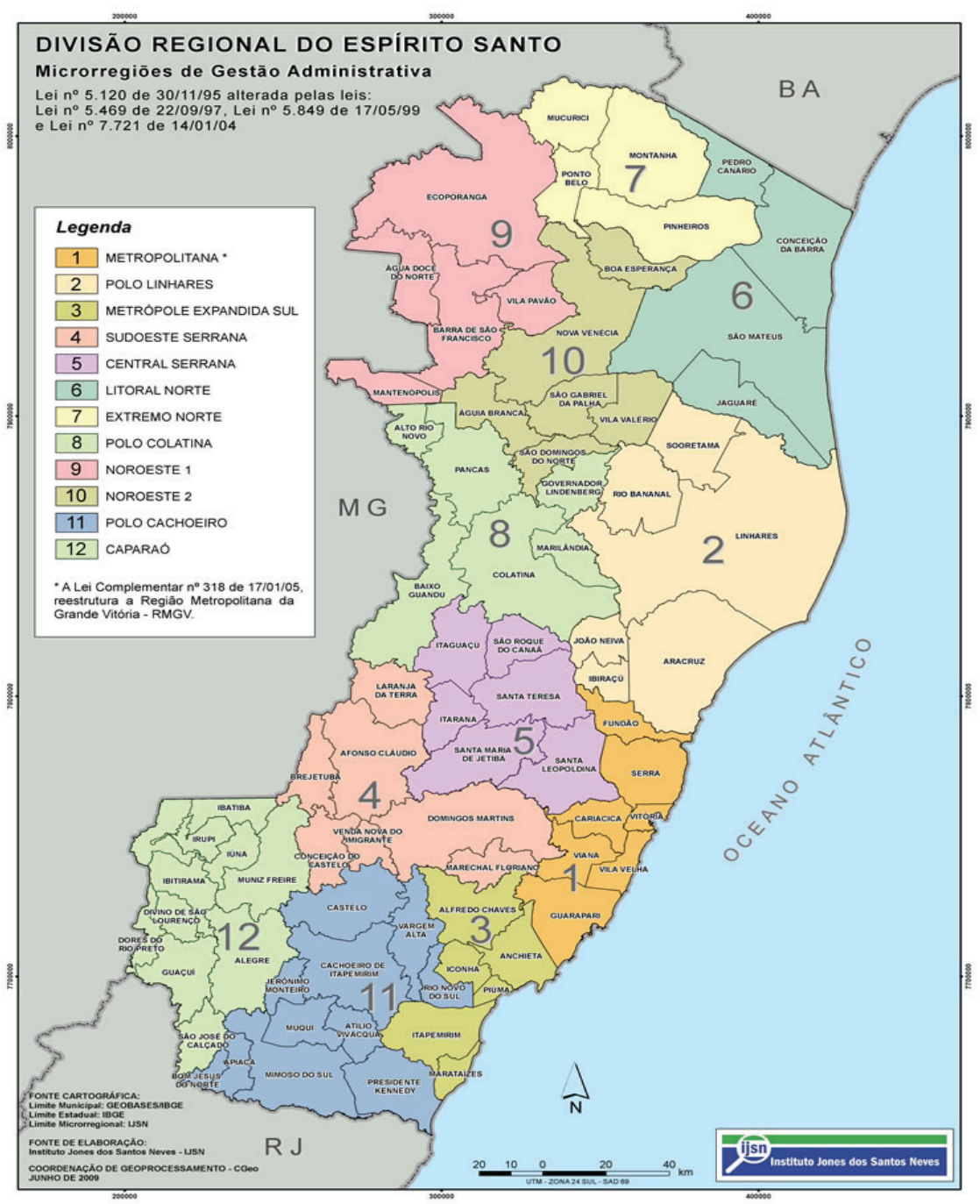

